\title{
Numerical benchmarking study of a selection of wave energy converters
}

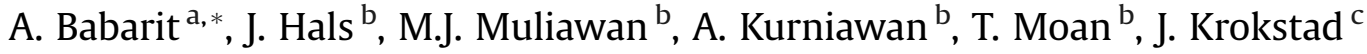 \\ a Laboratoire de Mécanique des Fluides, Ecole Centrale de Nantes, 1 rue de la Noe, 44300 Nantes Cedex 3, France \\ ${ }^{\mathrm{b}}$ Centre for Ships and Ocean Structures, Norges Teknisk-Naturvitenskapelige Universitet, Otto Nielsens v. 10, 7491 Trondheim, Norway

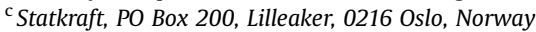

The aim of this study is to estimate the mean annual power absorption of a selection of eight Wave Energy Converters (WECs) with different working principles. Based on these estimates a set of power performance measures that can be related to costs are derived. These are the absorbed energy per characteristic mass $[\mathrm{kWh} / \mathrm{kg}]$, per characteristic surface area $\left[\mathrm{MWh} / \mathrm{m}^{2}\right]$, and per root mean square of Power Take Off (PTO) force $[\mathrm{kWh} / \mathrm{N}]$.

The methodology relies on numerical modelling. For each device, a numerical Wave-to-Wire (W2W) model is built based on the equations of motion. Physical effects are modelled according to the state-of-the-art within hydrodynamic modelling practise. Then, the W2W models are used to calculate the power matrices of each device and the mean annual power absorption at five different representative wave sites along the European Coast, at which the mean level of wave power resource ranges between 15 and $88 \mathrm{~kW}$ per metre of wave front. Uncertainties are discussed and estimated for each device.

Computed power matrices and results for the mean annual power absorption are assembled in a summary sheet per device. Comparisons of the selected devices show that, despite very different working principles and dimensions, power performance measures vary much less than the mean annual power absorption. With the chosen units, these measures are all shown to be of the order of 1 .

\section{Introduction}

In the last decade many projects for the development of wave energy converters (WECs) have emerged in places all around the world, especially in Europe. A review of technologies and working principles may be found in [1].

For devices that have been publicly announced, the available information is usually limited to sketches, pictures and animations, and in some cases, also dimensions and system layout. Only a few quantitative figures on the estimated or measured energy conversion are presently known. As a consequence wave energy sector is often seen as a confused and risky business from the investors and policy makers point of view. By providing estimates of annual energy absorption in realistic conditions for some of the most studied structures proposed for wave energy conversion, the first aim of this paper is to contribute to clarifying what can

\footnotetext{
* Corresponding author.

E-mail addresses: aurelien.babarit@ec-nantes.fr (A. Babarit), jorgen.hals@ntnu.no (J. Hals), made.muliawan@ntnu.no (M.J. Muliawan), adi.kurniawan@ntnu.no (A. Kurniawan), torgeir.moan@ntnu.no (T. Moan), jorgen.krokstad@statkraft.com (J. Krokstad).
}

reasonably be expected as the mean output of wave energy converters.

The second aim is to compare the selected technologies with reference to a set of quantitative measures that can be related with costs. To our knowledge, there is only a few published studies of this kind. One must notice the Danish Wave Energy Research program [2] which resulted in estimates of energy absorption and cost estimates for 15 different WECs. They were obtained through tank test experiments. It was shown that for all the considered devices, the capture width ratio ${ }^{1}$ varied between 4 and $30 \%$. Estimates for the cost of energy for prototypes indicate to be at best about $1 € / \mathrm{kWh}$. In [3], energy delivery and costs of 8 devices were assessed for potential deployment in a pilot plant in the US regarding energy production and costs. The methodology was based on information given by the developers. The study concluded that only the Pelamis was acceptable for selection at that time.

The present work is distinguished from these two previous studies by using numerical rather than experimental methods and by considering different WECs and performance measures. The

\footnotetext{
1 Ratio of absorbed wave power to the wave power flux times the typical width of the device.
} 
selected WECs are mainly based on the oscillating bodies working principle, with the exception of one floating Oscillating Water Column (OWC). The selected performance measures are:

- Annual absorbed energy.

- Annual absorbed energy per characteristic mass.

- Annual absorbed energy per characteristic surface area.

- Annual absorbed energy per unit of characteristic PTO force

The annual absorbed energy represents the income side of a wave energy project. It may be estimated once the external dimensions, working principle, machinery function and local wave resource are known. However, it is not a sufficient measure by itself because it is actually the average economic cost per kilowatt-hour over the device life span that is important, as this dictates whether a project may be realised or not. This requires cost estimation, which is a much more complex task since the costs of design, fabrication, installation, operation, maintenance, and eventually decommissioning have to be taken into account. As long as the technical solutions are uncertain or unknown on a detailed level, cost estimates are inevitably hampered by large uncertainties. That is why there has not been any attempt to derive them in this study. Instead, we chose to use performance measures that we believe are good cost indicators.

It may be tempting to say that the absorber structure fabrication cost will depend on its displaced mass as it seems to be the case in shipbuilding [4]. However, this performance measure is not fair when most of the mass is water or concrete ballasts like it is the case for some WECs. To account this fact, one could also consider the wetted surface area of the WEC as an indicator of the costs of the hull.

In this study the characteristic mass has been taken to include the mass of foundations for devices that find their force-reference in the sea bottom. For self-referencing floating systems, the mooring layout has not been included in the analysis but the characteristic mass is set equal to $(1.15 \pm 0.1)$ times the displaced mass in order to roughly account for the mooring system, although this may be very uncertain. For the characteristic wetted surface area, foundations are included in the same way, but no additional surface area has been attributed to mooring systems.

It is expected that the PTO system will be a significant source of cost as well. It is well known that for the same amount of output power, the higher the velocity the cheaper the PTO system. Conversely, the higher the PTO forces, the more expensive the PTO system will be. Therefore, the amount of absorbed energy per unit of characteristic PTO force is expected to be a relevant measure for the cost of the PTO system. In this study the characteristic PTO force was chosen as the root mean square value over a year.

This paper is organised in three parts. The first part describes the case studies; both selected WECs and selected sites. In the second part, the modelling approach is explained. The results in terms of power matrices, energy absorption and cost-related performance measures are given and discussed in the last part.

\section{Case studies}

\subsection{Devices}

Eight devices with different working principles and/or dimensions were considered in the case studies. A short description is provided in the following. Details on dimensions and parameters which were used can be found in [5].

The geometry and configuration of each of the eight devices were inspired by the design of well-known wave energy converters currently under development by different technology companies. It should however be noted that there may be significant and important differences both in geometry and configuration between the devices studied here and their inspirators, thus also the performance may differ.

\subsubsection{Small bottom-referenced heaving buoy (Bref-HB)}

This wave energy converter is inspired by the Seabased WEC which is currently in development in Sweden. Fig. 1 shows its different components.

The device consists of an axi-symmetric buoy with ellipsoidal cross section floating on the ocean surface. Through a wire it is connected to a machinery unit standing at the sea bottom. The machinery consists of a linear generator placed inside a steel hull mounted on a concrete ballast structure. Under wave action, the buoy moves in surge and heave, resulting in a wire pull that drives the generator.

A simplified sketch of the system and its main dimensions and parameters are shown in the device summary sheet, Fig. 12. Note that, for this device, the anchoring system is an essential component as it provides the reaction point. Therefore, it was included in the characteristic surface area and characteristic mass measures for the system. The characteristic surface area was estimated to be about $42 \mathrm{~m}^{2}$ and the characteristic mass to be about 31 tonnes.

\subsubsection{Bottom-referenced submerged heave-buoy (Bref-SHB)}

This wave energy converter is inspired by the Ceto WEC which is currently being developed in Australia and France. A picture showing the buoy is found in Fig. 2 .

The working principle of this device is close to the previous one. The main differences are that the buoy has a diameter twice as large, that it is fully submerged and that the PTO system is hydraulic. Still the PTO is placed on the sea bottom and connected to the buoy through a tether.

Fig. 13 shows simplified sketch of the system, as well as a table giving the main dimensions and parameters. As for the previous device, the anchoring system was included in the characteristic surface area and characteristic mass measures for the system. The characteristic surface area was estimated to be about $220 \mathrm{~m}^{2}$ and the characteristic mass to be about 200 tonnes.

\subsubsection{Floating two-body heaving converter ( $F-2 H B)$}

This system is inspired by the Wavebob WEC which is currently under development in Ireland. Fig. 3 shows a picture of the $1 / 4$ th scale model of the Wavebob, which was tested at sea in the Galway bay in Ireland.

It is an axi-symmetric, self-reacting point absorber, operating in the heave mode. It is composed of a torus sliding along a vertical float. The hydraulic PTO system is driven by the relative motion between the two bodies. A simplified sketch is shown in Fig. 14.

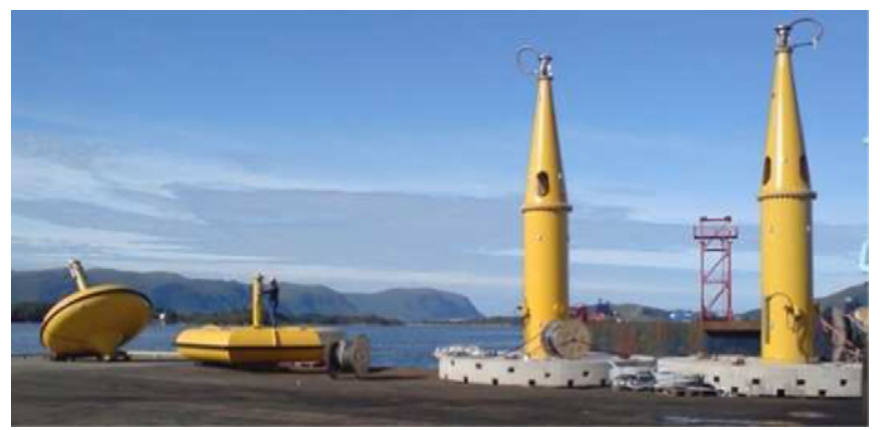

Fig. 1. Components of the Seabased WEC. 


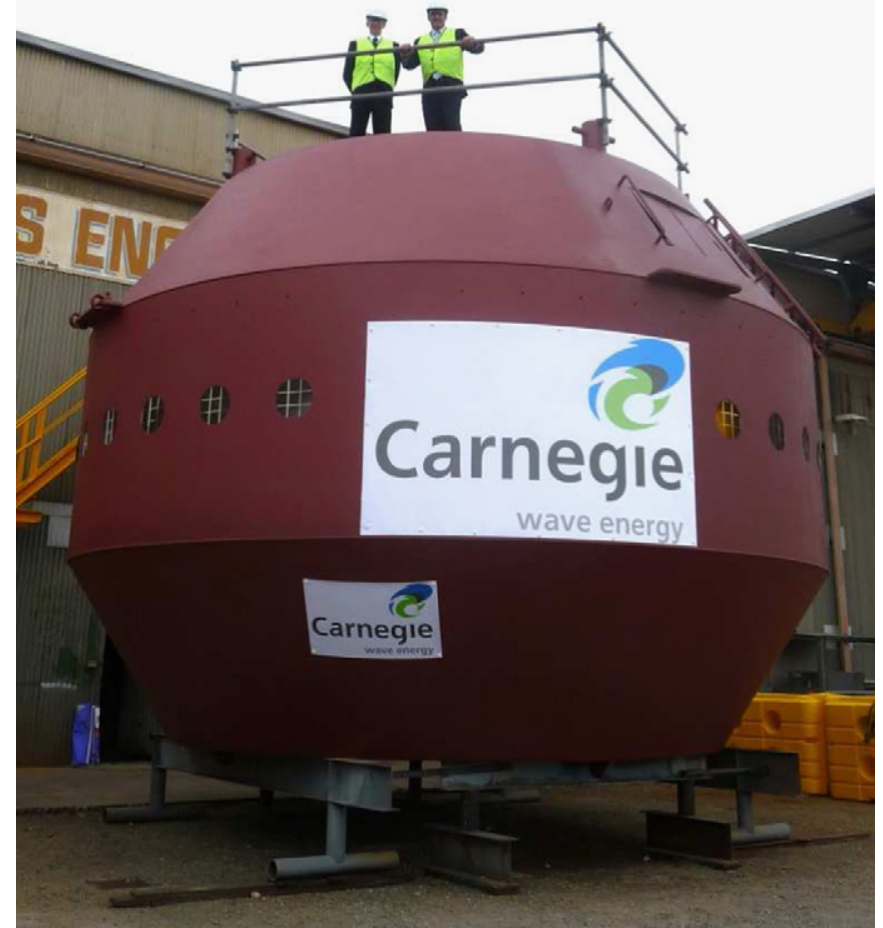

Fig. 2. Picture of the unveiling of the Ceto buoy.

Contrary to the first two systems, this system does not need to react against the seabed, so it can be installed in deep water. The role of the mooring system is to counteract drift and current forces. Therefore, the weight of moorings and anchors is expected to be small, so it was not taken into account in surface area and mass estimation of the system. The characteristic mass is then about 5700 tonnes and the wetted surface area about $2100 \mathrm{~m}^{2}$.

\subsubsection{Bottom-fixed heave-buoy array (B-HBA)}

This system is inspired by the Wavestar WEC, under development in Denmark. In Fig. 4 the test section currently being tested at

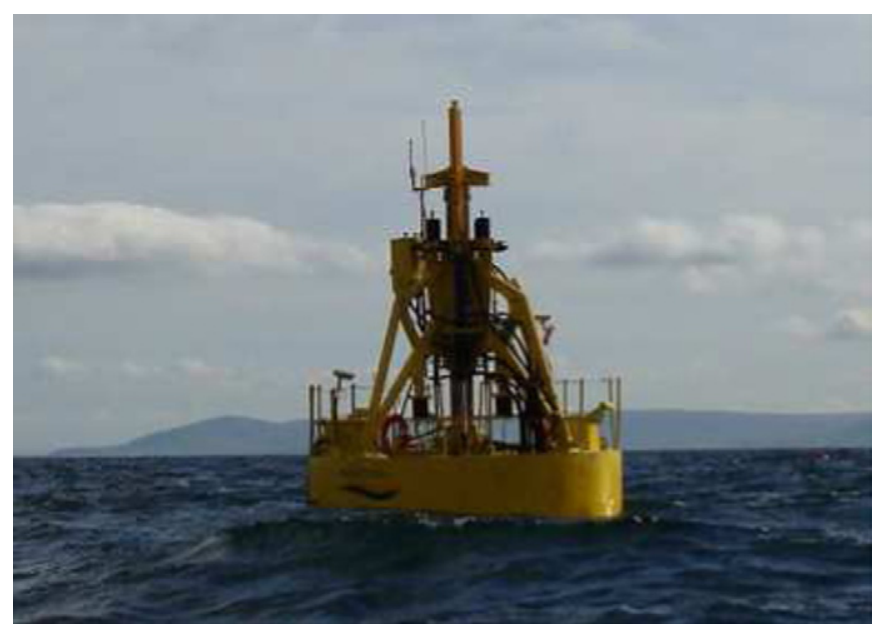

Fig. 3. 1/4 scale model of the Wavebob at sea.

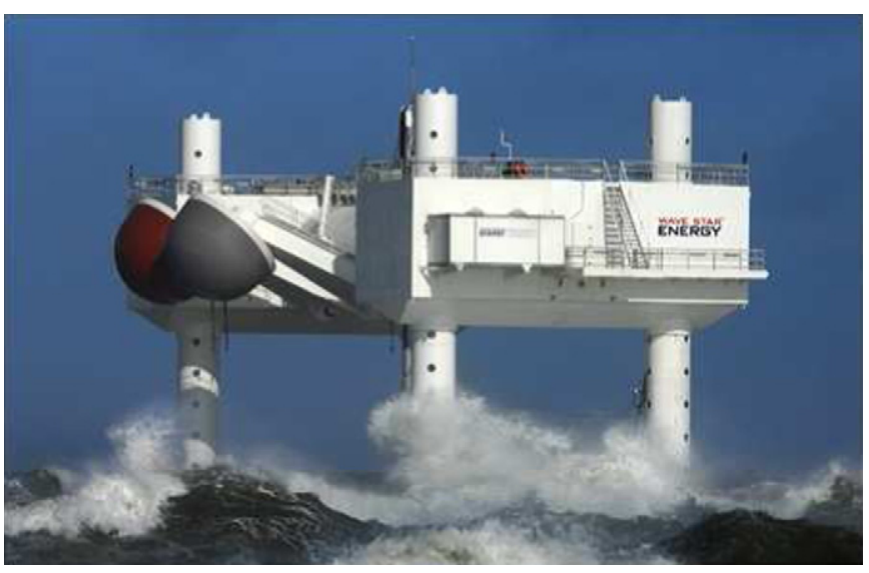

Fig. 4. Picture of the test section of the Wavestar WEC.

Hanstholm in Denmark is shown with its buoys and platform in survival mode.

In its full size the system is composed of many floats connected to a single jack-up structure. The jack-up structure stands on the seabed and provides a fixed reference to the floats. The floats are submerged hemispheres. Each one is connected to the main structure via an arm and a hinge. With the action of the waves, each float moves up and down. The relative motion between floats and the structure is converted into useful energy via hydraulic rams. In the present analysis, the number of buoys was set to 20 .

A sketch of the system is shown in Fig. 15. As the jack-up structure is an essential part of the system, it was included in the measures of mass and surface area. The characteristic surface area was estimated to about $4350 \mathrm{~m}^{2}$ and the characteristic mass to about 1600 tonnes.

\subsubsection{Floating heave-buoy array (F-HBA)}

This system is inspired by the Pontoon Power Converter, under development in Norway. Fig. 5 shows an artistic view of the system.

It is a multibody floating WEC, composed of many heaving buoys connected to a common submerged reference structure. This structure is composed of an arrangement of a single support structure and a series of ballasts baskets, connected through tension wires, as illustrated in Fig. 5. The total buoyancy force from the buoys is balanced by net gravity forces of the bridge and the ballast baskets. The buoys are connected to the submerged structure via a hydraulic PTO system, which converts the energy. In the analysis provided here, the number of buoys was set to 10 .

A sketch of the system is shown in Fig. 16. As the submerged structure is an essential part of the system, it was included in the mass and surface area measures. The characteristic surface area was estimated to about $4800 \mathrm{~m}^{2}$ and the characteristic mass to about 5200 tonnes.

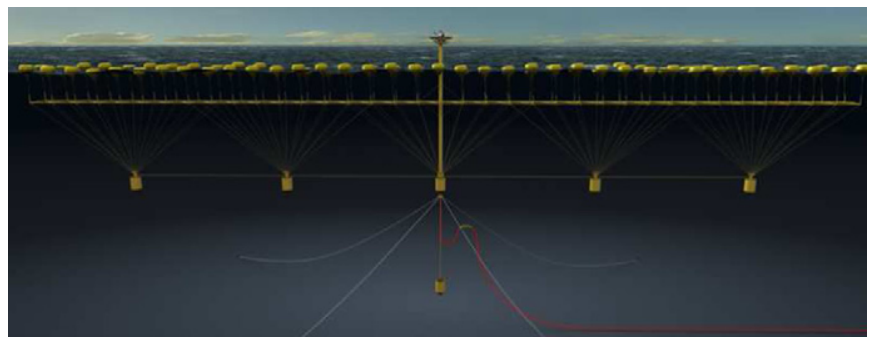

Fig. 5. Artistic view of the Pontoon Power Converter WEC. 


\subsubsection{Bottom-fixed oscillating flap (B-OF)}

This system is inspired by the Oyster WEC, under development in Scotland by the company Aquamarine Power. Fig. 6 shows the Oyster2 geometry.

This device is a simple pitching flap, oscillating about a fixed axis close to the sea bottom, and so is suitable for shallow and intermediate water depth. It has a hydroelectric machinery system, where a pump placed at the rotating shaft pumps pressurised hydraulic oil to a shoreline station. There the hydraulic energy is used to drive an electric generator.

A sketch of the system and main dimensions and parameters are shown in Fig. 17. The characteristic mass was estimated to be about 3800 tonnes and the characteristic surface area to be about $2020 \mathrm{~m}^{2}$. It includes an estimated gravity based structure designed to withstand the horizontal forces.

\subsubsection{Floating three-body oscillating flap device (F-3OF)}

This device is inspired by the Langlee WEC, currently under development in Norway. Fig. 7 shows an artistic view of a full scale Langlee WEC.

It consists of four hinged flaps which are all connected to the same frame. Via PTO systems, the relative motion between each flap and the main frame is converted into useful energy.

A sketch of the system analysed in this work is shown in Fig. 18. The characteristic mass of the flaps and supporting structure is then estimated to about 1600 tonnes. The characteristic surface area is about $2200 \mathrm{~m}^{2}$

\subsubsection{Floating oscillating water column (F-OWC)}

This device is inspired by the OE Buoy which is developed by Ocean Energy Ltd. in Ireland. Fig. 8 shows a picture of the $1 / 4$ th scale model of the OE Buoy under testing at sea in Galway Bay in Ireland.

The floating oscillating water column device is a particular type of OWC device known as the backward bent duct buoy (BBDB) first proposed by Masuda [6]. It has a single air chamber and is free to move in six degrees of freedom. The water column has a submerged opening aligned downstream of the incident wave propagation direction. The device is constructed of thin steel walls enclosing the water column. The power conversion is provided by means of an air turbine connected to an electric generator. The motion of the water column relative to the OWC body creates

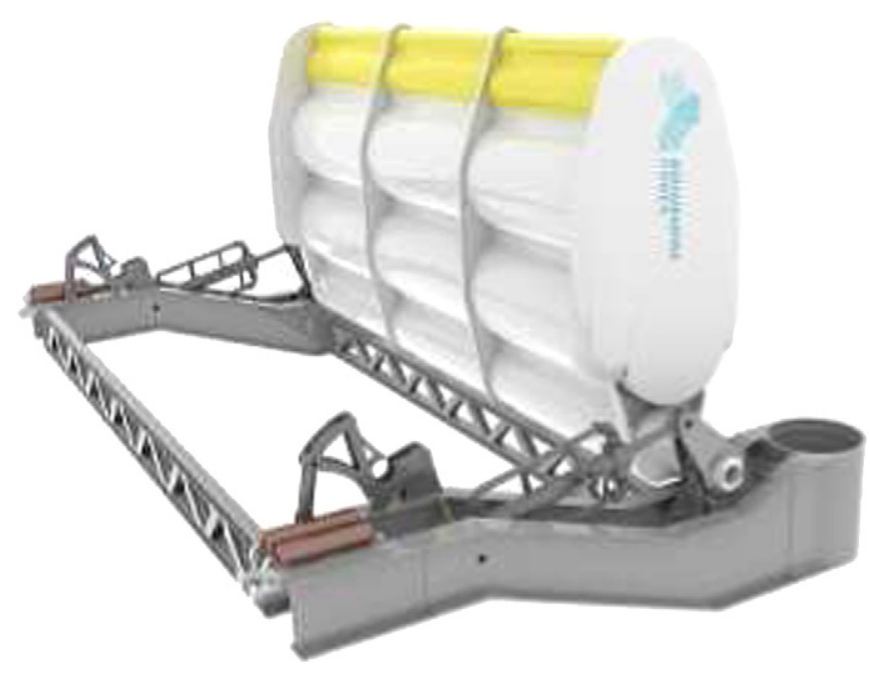

Fig. 6. Picture of the Oyster2 wave energy converter.

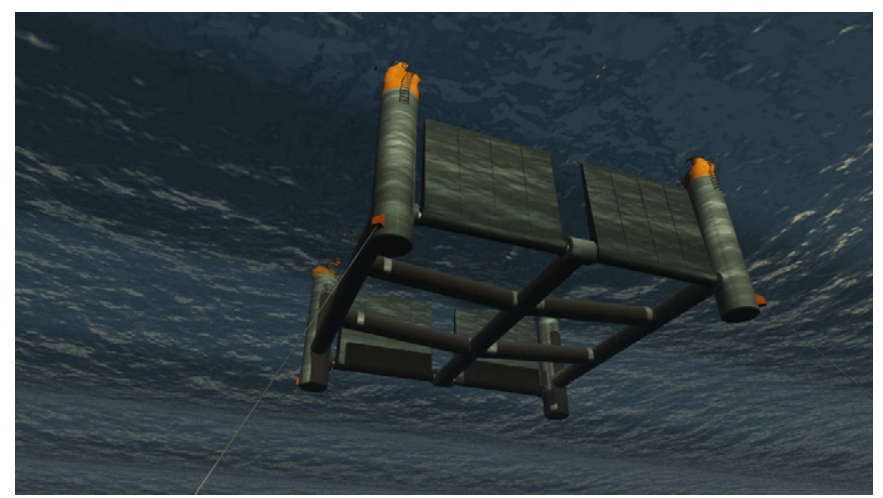

Fig. 7. Artistic view of the Langlee WEC.

oscillating pressure in the chamber and air flow through the turbine. A relief valve provides a way to keep the pressure in the air chamber within acceptable limits to prevent the turbine from stalling.

A sketch of the system is shown in Fig. 19. The characteristic mass is about 1800 tonnes and its characteristic external surface area is estimated to about $6500 \mathrm{~m}^{2}$.

\subsection{Sites}

As the level of mean wave energy transport varies from one place to another, it is important to consider several sites with different wave resource in order to evaluate the influence this has on the benchmarking performance measures. In this study, wave data statistics from five locations along the Atlantic coast of Europe were used, as indicated in Fig. 9.

The wave statistics are shown in Fig. 10. For the SEM-REV and Yeu island sites, the data come from the ANEMOC data base. ${ }^{2}$ Statistics for the EMEC and Lisbon come from [7]. For Belmullet, they come from the Irish Marine Institute. ${ }^{3}$

Although the sites are located at different finite water depths ranging from 40 to $100 \mathrm{~m}$, deep water was assumed for the numerical simulations. It means that the computed responses are slightly different from those that would be found if the true water depth were used. However, some of the considered devices are designed for shallow water. When waves enter shallow water power is lost due to various dissipation mechanisms [8]. Assuming that the wave data statistics in shallow water is the same as in deep water would have lead to overestimates of energy absorption for devices in finite water depth. In order to make a more even basis for the comparison of deep-water and shallow-water results, the deep water data statistics were processed to synthesise shallow water data statistics that take the energy loss into account. According to [9], this energy loss may be expected to be around $10 \%$ in typical wave conditions. Therefore, shallow-water wave data was generated assuming that for each wave frequency component of each sea state, $90 \%$ of the energy is transferred from deep to shallow water depths (13-20 m).

Table 1 shows the mean wave power level for each of the five sites, in function of the water depths used in the simulations here. The levels of resource ranges from 15 to $80 \mathrm{~kW} / \mathrm{m}$, which is believed to cover possible locations for wave energy plants quite well.

\footnotetext{
2 candhis.cetmef.developpement-durable.gouv.fr. Accessed May 2010.

3 www.marine.ie. Accessed May 2010.
} 


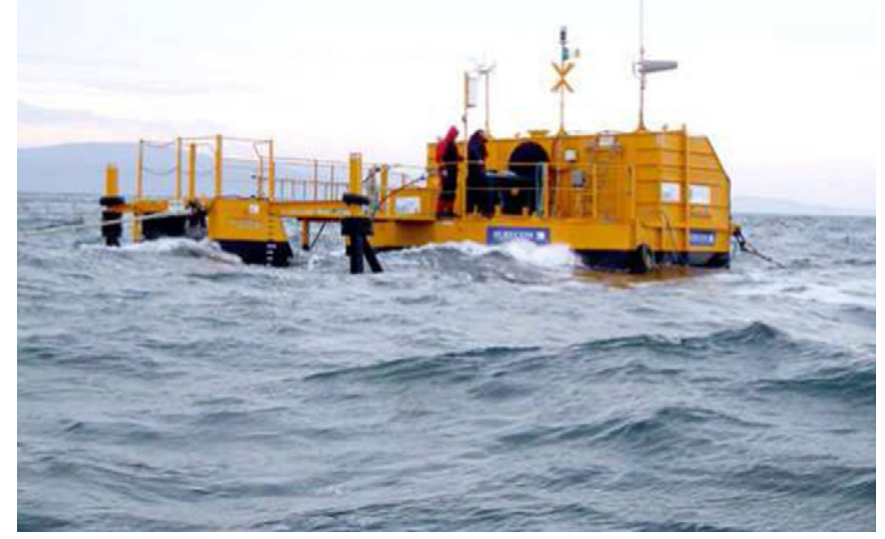

Fig. 8. 1/4 scale model of the OE buoy at sea.

\section{Methods}

\subsection{Numerical model}

An estimate of the wave energy absorption of a particular device at a particular location can be obtained by multiplying the power matrix of this device with the scatter diagrams of wave statistics at this location. As the scatter diagrams are available (or processed to be available at the water depth of interest), the problem reduces to determining the power matrix of each device.

The power matrices were determined by using numerical models. For each device, a numerical Wave to Wire time-domain model was built. Essentially, it consists of integrating the following formal equation of motion:

$$
\begin{aligned}
\left(M+\mu_{\infty}\right) \ddot{X}= & F_{\mathrm{ex}}-\int_{0}^{t} K(t-\tau) \dot{X}(\tau) \mathrm{d} t+F_{H}+F_{\mathrm{PTO}}+F_{V}+F_{\mathrm{es}} \\
& +F_{M}+F_{\text {Coriolis }}
\end{aligned}
$$

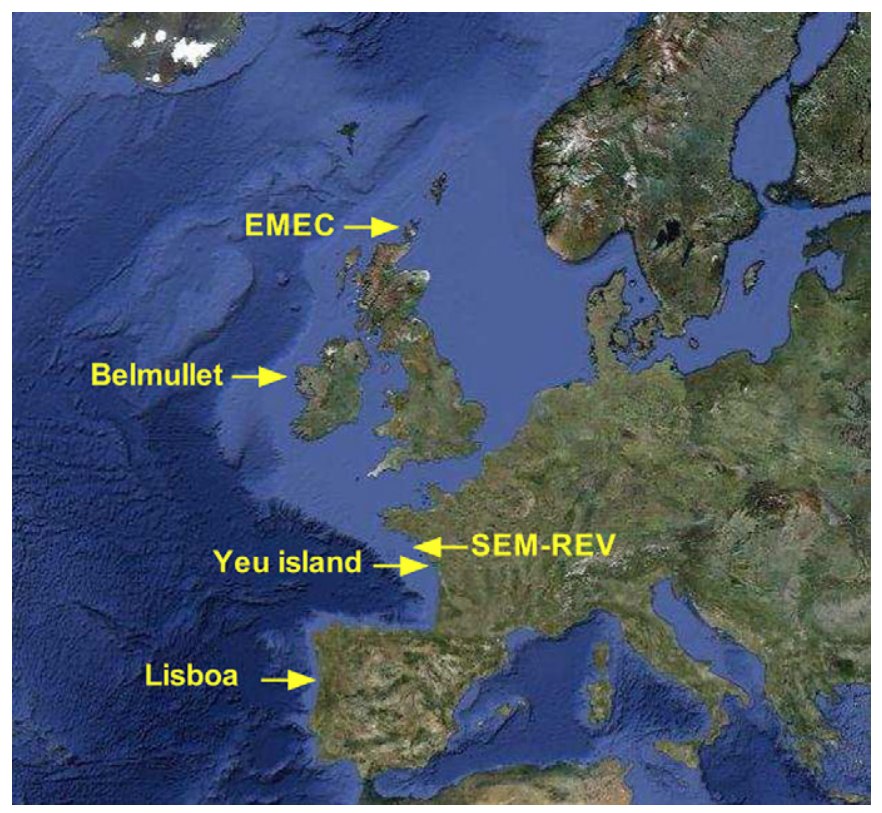

Fig. 9. Sites from which annual wave data statistics were taken.
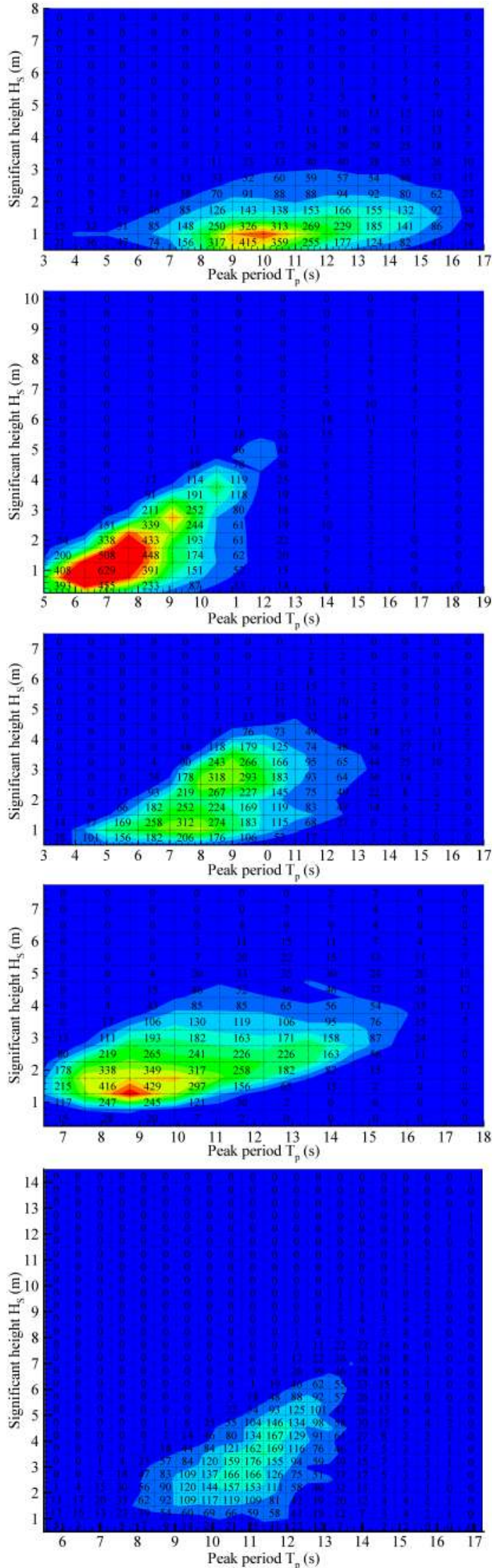

Fig. 10. Scatter diagrams of wave data statistics for, from top to bottom, SEM-REV, EMEC, Yeu island, Lisbon, Belmullet. 
Table 1

Mean annual wave power level in function of site and water depth.

\begin{tabular}{llll}
\hline \multirow{2}{*}{ Site } & \multicolumn{2}{l}{ Wave power resource $(\mathrm{kW} / \mathrm{m})$} \\
\cline { 2 - 4 } & in deep water & $20 \mathrm{~m}$ depth & $13 \mathrm{~m}$ depth \\
\hline 1. SEM-REV & 14.8 & 13.3 & 13.3 \\
2. EMEC & 21.8 & 18.7 & 18.7 \\
3. Yeu island & 26.8 & 22.4 & 22.4 \\
4. Lisbon & 37.5 & 33.7 & 33.7 \\
5. Belmullet & 80.6 & 72.5 & 72.5 \\
\hline
\end{tabular}

in which:

- $X, \dot{X}, \ddot{X}$ are the position, velocity and acceleration vectors of the considered device. They have as many rows as the device has degrees of freedom.

- $M$ is the mass matrix of the device. Depending on the device and whether the equation of motion was linearised or not, it is not necessarily constant. It can be a function of the position and velocity vectors $X$ and $\dot{X}$.

- $F_{\text {ex }}, \mu_{\infty}$ and $K(t)$ are respectively the wave excitation force, the added mass matrix and the memory function of the radiation forces.

- $F_{H}$ is the hydrostatic force, resulting from the combined action of the gravity and buoyancy force.

- F Рто is the force applied by the Power Take Off (PTO) system.

- $F_{V}$ is a damping force that depends quadratically on the velocities, and which aims at taking into account the effect of viscous losses.

- $F_{M}$ is the mooring force.

- $F_{\mathrm{es}}$ is a force which aims at taking into account the effect of end stops in the PTO mechanism, if any.

- FCoriolis is a force which comes from non-linear terms in the mechanical part of the equation of motion.

Models and modelling assumptions used for these force terms are explained in more detail in the following sections.

In the present analysis, drift forces, current forces and wind forces were not considered because we believe that they have no or very small influence on the potential for energy absorption.

\subsubsection{Wave-structure interaction}

For modelling waves and wave-structure interaction, linear potential flow theory was used. It relies on assumptions of inviscid and incompressible fluid, irrotational flow, small amplitudes of motion of the device relative to its dimension and small wave amplitudes relative to the wavelength.

For wave energy application, the agreement between linear theory and experiments is usually good in small to moderate sea states, as it has been shown in many studies; see [10-14] for examples. However, there can be characteristic discrepancies in severe sea states, or in wave conditions that excite resonances, because of non-linear and/or viscous effects. To our experience, linear theory will lead to an overestimation of the dynamic response and the energy absorption in these cases. We acknowledge that it brings uncertainty in the results. However, as the aim of the study is to provide upper estimates for wave energy absorption, we believe that this uncertainty is acceptable.

In addition, we assumed that waves are mono-directional. It has no consequence for axi-symmetric devices, but it can introduce a bias in other cases. However, it was shown in [15] that the effect of directionality was smaller than $10 \%$ when varying the wave direction from $-45^{\circ}$ to $+45^{\circ}$, in the case of the directionality-dependent SEAREV device. The sites which were considered in this study being along the West coast of Europe, most of the characteristic wave resource will come from the South-West to North-West direction. The mooring system of floating devices might well allow some alignment of the devices with the wave direction, and for bottomfixed devices refraction at shallow water tends to align the wave crests with the coastline. Taking this into account, we conclude that directionality should not have a significant effect on the main results of this study.

Using linear potential theory, the pressure force resulting from wave-structure interaction can be written as the sum of a wave excitation force $F_{\mathrm{ex}}$ and a radiation force $F_{\mathrm{rad}}=-\mu_{\infty} \ddot{X}$ $-\int_{0}^{t} K(t-\tau) \dot{X}(\tau) \mathrm{d} t$. The wave excitation force can be related to the incident wave field spectrum $S(f)$ through the relations:

$\left.F_{\mathrm{ex}}(t)=\Re \sum_{i}\left(\sqrt{2 S\left(f_{i}\right) \Delta f}\right) \bar{F}_{\mathrm{ex}}\left(f_{i}\right) e^{i\left(2 \pi f_{i} t+\phi_{i}\right)}\right)$

in which $\Delta f$ is an adequate frequency step, $\phi_{i}$ are a set of random phases and $\bar{F}_{\text {ex }}$ are complex vectors of wave excitation force per metre of wave amplitude in the frequency domain.

The hydrodynamic functions $K$ and the coefficients $\bar{F}_{\text {ex }}$ and $\mu_{\infty}$ were calculated using the BEM (Boundary Element Methods) codes WAMIT [18] or Aquaplus [19]. In each case, mesh convergence was checked by comparing the obtained coefficients for two different mesh refinements. Convergence was always reached.

\subsubsection{Quadratic damping force}

In many cases, linearity and irrotationality assumptions of linear potential flow theory are likely to be violated. Neglecting this would in these cases lead to numerical prediction of unrealistically large amplitude of motions, and thereby also energy absorption.

In reality, non-linear effects and viscous effects such as flow separation will limit the amplitude of motion. A common way of modelling the latter effect is to add a quadratic damping term similar to the drag term in Morison's equation [20]:

$F_{V}=-\frac{1}{2} \rho C_{D} A_{D}\left|V-V_{0}\right|\left(V-V_{0}\right)$

in which:

- $V$ and $V_{0}$ are respectively the device velocity and undisturbed flow velocity.

- $A_{D}$ and $C_{D}$ are respectively a matrix of characteristic areas and a matrix of drag coefficients.

Here, the difficulty lies in the estimation of the drag coefficients $C_{D}$. There are many experimental results available in the literature, coming from research on hydrodynamic forces on risers and other offshore equipments in the Oil \& Gas industry. In this study, drag coefficients were estimated based on that knowledge. Reference [16] was used as the main source.

It is realised that this methodology of selecting the drag coefficients brings a large uncertainty in the models. Therefore, it has been important to perform analysis of the absorbed energy's sensitivity to variations in the drag coefficient. For each device, drag coefficients were varied from one quarter to twice their nominal values. Corresponding variation on the energy absorption was retained as the uncertainty bar. Although the drag coefficients were varied by a factor of up to 4 , one should notice that the influence on the energy absorption was never found to be more than $30 \%$, whatever the device. 


\subsubsection{Power take-off force}

The power take-off (PTO) is the system which converts the mechanical energy of the device into electricity. In the case of an OWC it will be an air turbine such as a Wells turbine. In the case of wave activated bodies WECs, it can be based on hydraulic components (hydraulic rams and motors) combined with an electric generator, as assumed in [21]. Or it can be fully electric, like in [22] or [23].

The Wells turbine has an almost linear relationship between pressure drop and volume flow [24], and may be well modelled as a simple linear damper. Also the fully electrical PTOs are often controlled to yield a linear relationship between force and velocity, and may then be modelled as a linear damper. In the case of hydraulic PTO systems, a better representation is achieved by using a Coulomb damping model. Details of the PTO modelling are given below.

3.1.3.1. Linear PTO model. Depending on the considered WEC, additional inertia or spring effects may improve the power absorption ability. Such effects were included in the PTO force together with the damping effect when it made sense from an engineering point of view. With both inertia, damping and spring effects, the PTO force in the general case reads:

$F_{\text {PTO }}=-M_{\text {PTO }} \ddot{X}-B_{\text {PTO }} \dot{X}-K_{\text {PTO }} X$

In this study, one should note that only the case of positive machinery spring coefficients $K_{\text {PTO }}$ was considered. The reason is that the effect of positive values can be efficiently obtained with mechanical components. Negative spring effects are harder to obtain in reality and usually involves feeding large amounts of reactive power through the machinery equipment [17]. Dissipative losses may make such solutions less attractive, and negative mass and spring coefficients have therefore not been included as an option in this study.

3.1.3.2. Hydraulic PTO model. In the case of hydraulic PTO, a Coulomb damping model was used. As with the linear PTO, a spring or additional mass term was included as well as the damping term when it made sense from an engineering point of view. In the general case, the PTO force reads:

$F_{\mathrm{PTO}}=-M_{\mathrm{PTO}} \ddot{X}-C_{\mathrm{PTO}} \operatorname{sign}(\dot{X})-K_{\mathrm{PTO}} X$

The numerical implementation of the Coulomb damping force is difficult because the derivative is infinite at $\dot{X}_{i}=0$. This can lead to non-physical oscillations of the velocity around 0 , subsequently leading to erroneous values for power absorption. Hence, in practise perfect Coulomb damping is replaced by an approximate Coulomb damping, in which the damping force is supposed to have a finite (but still high) derivative in the range about zero velocity. The principle is illustrated in Fig. 11.

Mathematically, the PTO force with approximate Coulomb damping reads

$F_{\mathrm{PTO}}(A)=-M_{\mathrm{PTO}} \ddot{X}-\min \left(G_{\mathrm{PTO}}|\dot{X}|, C_{\mathrm{PTO}}\right) \operatorname{sign}(\dot{X})-K_{\mathrm{PTO}} X$

In this study, the coefficient $G_{\text {PTO }}$ was set to 100 times the dry mass plus added mass coefficient.

3.1.3.4. Optimisation of the PTO coefficients and control. The PTO system is an essential part of any WEC. It is well known that it has a large influence on the dynamic response of the system. Varying its properties give some freedom to tune the dynamic response of the

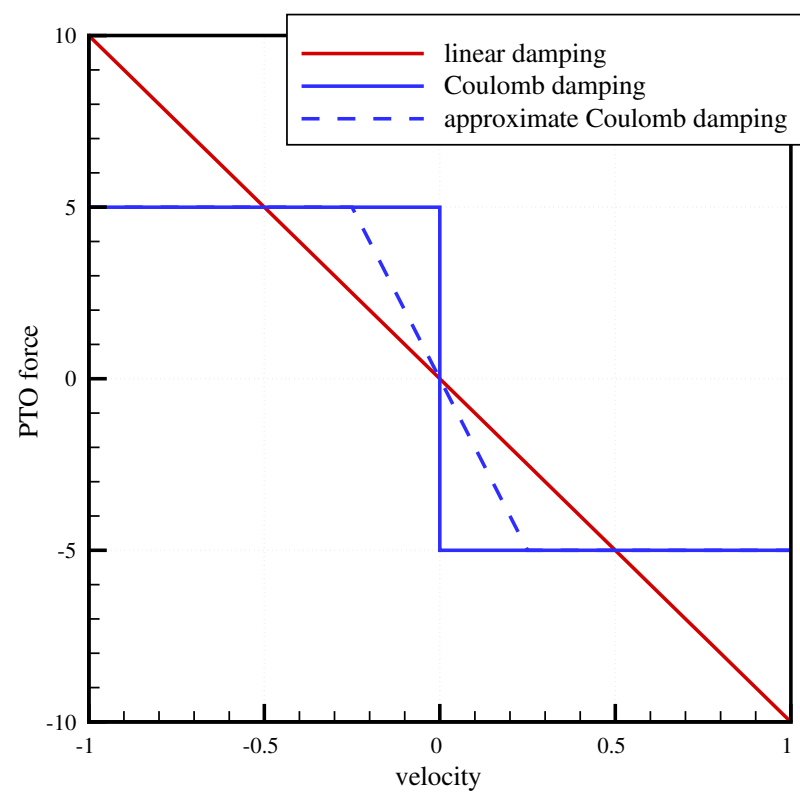

Fig. 11. PTO force vs velocity when PTO is linear, Coulomb damping and approximate Coulomb damping.

system in order to optimise the energy absorption abilities of the WEC.

This tuning can be done on a wave by wave basis, or on a sea state basis. The first option is a real time control. Together, with efficient control algorithms [25-30], it has the ability to significantly increase the energy absorption, by a factor of up to 2-3. However, in principle this kind of control requires some knowledge of the future excitation force, which means we need to somehow measure and predict the incident wave. Although there is promising on-going research on this topic [31], it is not a practical option at the current time. Therefore, it was not considered in this study.

The second option - tuning of the PTO parameters on a sea state basis - is much easier to achieve in practise, because it only requires the knowledge of the current sea state. In practise, one can measure the sea spectrum at some distance of the WEC with a wave data buoy and adjust the PTO settings accordingly. Other alternatives include the use of extremum-seeking control as proposed in [30]. In the present study the first of the spectrum measurement approach is assumed, where the PTO parameters are optimised for each state. Optimisation was made using brute force, i.e. iterative simulation using a maximum-search algorithm.

It should be noted that, in principle, such iterative search may reach a local maximum, not the global maximum. However, it was not found to be an issue in this study.

\subsubsection{End-stop forces}

Some of the considered devices have end stops, which were implemented in the numerical model by adding springs with large stiffness coefficients. They become active as soon as the amplitude of the motion is larger than the amplitude constraint. This was formulated as follows:

$$
\begin{aligned}
F_{\mathrm{es}}= & -K_{\mathrm{es}} \operatorname{diag}\left(X+X_{\mathrm{es}}\right) u\left(-X-X_{\mathrm{es}}\right) \\
& -K_{\mathrm{es}} \operatorname{diag}\left(X-X_{\mathrm{es}}\right) u\left(X-X_{\mathrm{es}}\right)
\end{aligned}
$$

in which $K_{e s}$ is the stiffness coefficient of the end stop spring; $u(\cdot)$ is the element-wise Heaviside step function and $X_{e s}$ is the amplitude constraint vector 


\subsubsection{Mooring force}

In [32] and [33], it was shown that at least for slack-moored heave-buoy systems the influence of the mooring system on the energy absorption is negligible. Therefore, mooring systems were represented by simple linear springs adjusted to keep the device in place with minimum influence on the power absorption.

\subsection{Implementation and verification}

For each particular device (except the floating heave-buoy array), the corresponding equation of motion was derived. Then, a numerical Wave to Wire model was built. The implementation was made in Fortran90. A second-order predictor-corrector time integration scheme was used.

Whenever possible, results from the numerical model were compared with publicly available information. In the cases of the small bottom-referenced heaving buoy, the floating two-body heaving converter, the bottom-fixed heave-buoy array, the bottom-fixed oscillating flap and the floating three-body oscillating flap device, references [22,34-37] were used, respectively. A very good agreement was found. In some cases, limited differences were found, because of different dimensions or control strategies of the PTO systems. Details of the comparisons, of the equations and of the models can be found in [5]. The numerical models are available from the authors upon request.

In the particular case of the floating heave-buoy array, the commercial SIMO software [38] was used. SIMO is a computer program developed by Marintek for simulating motions and station-keeping behaviour of complex systems of floating vessels and suspended loads. SIMOs essential features for the present analysis is its flexible modelling of multibody systems that accommodate introduction of PTO setting, end stops as well as hydrodynamic coupling between the bodies. In total, there are 13 bodies included in the present model. It consists of 10 buoys, a submerged support structure and 2 ballast baskets. The hydrodynamic properties of those bodies including the hydrodynamic interaction between the 10 buoys are calculated in the frequency domain using HydroD [39] and then applied in SIMO to solve the equation of motion of the full system for a given sea state in time domain. More illustration and discussion on how to use SIMO features to model PTO system, end stops and wires for multibody WEC may be found in [32].

\section{Results \& discussion}

Using the Wave to Wire models, the power matrices of each device were computed. By multiplying them with the wave scatter diagrams at each site, the annual mean absorbed power of each device at each site was derived. Results are reported in the devices' summary sheets, see Figs. 12-19.

For the bottom-referenced submerged heave-buoy and the bottom-fixed heave-buoy array, both the linear PTO and the hydraulic PTO (Coulomb damping) models were implemented. Unlike [28], no increase in energy absorption was observed with the Coulomb damping model in comparison with the linear model. Actually, Coulomb damping model led to a reduction in energy absorption by $20 \%$ in the case of the bottom-referenced heavebuoy, and by a few percents in the case of the bottom-fixed heavebuoy array. Therefore, results are reported only for the case of the linear PTO model, except for the floating heave-buoy array for which only Coulomb damping was considered.

From one device to another, depending on the site, one can see that mean annual power absorption figures are very different, ranging from 2 to almost $800 \mathrm{~kW}$. Of course, this was to be expected as the working principles and the sizes are very different. As also expected, one can notice that mean annual power absorption varies with the site. It is worth noticing that an increase in the available wave power resource does not necessarily mean an increase in mean annual absorbed power, as can be seen in the case of devices 5 and 7 for the Lisbon and Yeu sites. The reason is that for the Lisbon site, waves are much longer than at Yeu. As the waves are longer, the wave resource is larger, but at the same time it is more difficult for the devices 5 and 7 to efficiently capture these long waves. Hence, in the end, despite a larger resource, there is less energy absorbed.

Large variations are also found on capture width ratios from one device to another, ranging from $4 \%$ for the small bottomreferenced heaving buoy to $70 \%$ for the bottom-fixed oscillating flap. However, one can see that the variations of the three other performance measures (energy per characteristic mass, per characteristic surface area and per RMS of PTO force) are much more limited, with a maximum to minimum ratio less than 5 at a given site. In the following this will be discussed more in detail. We look first at the uncertainties associated with the present modelling approach.

\subsection{Estimation of uncertainties}

Numerical modelling was used. It relies on mathematical models for each component of the device, which are based on several assumptions and approximations. Therefore, it is acknowledged that the behaviour of an actual system could deviate from what is predicted by the numerical model.

In the particular case of strong sea states, it is expected that the deviation between the response of the actual device and its numerical model can be large. However, one should note that the quantities derived in this study are averaged values over a normal year. Then, errors are averaged too, so they are expected to be smaller.

Moreover, one should also recall the primary objective of this study: it is to derive estimates of mean annual power absorption for a selection of wave energy devices. From our experience, it is believed that if the behaviour of the numerical model deviates from the actual behaviour, then the trend of the deviation will be to overestimate the dynamic response of the system, and then also the energy absorption. Therefore, the numbers given here are believed to be in the upper range of what can be achieved with these instances of each type of device.

Finally, the modelling approach is the same for all devices. Therefore, it is expected that even if the numbers are not perfectly exact, the trends observed in comparisons between each technology should be correct.

To get an idea of the error bars, an uncertainty analysis was performed. Estimation of the drag coefficient was identified as the main error source for almost all of the devices (see the discussion on the error sources for each component of the system in Section 3). Hence, a sensitivity analysis was carried out as described in Section 3.1.2. Uncertainty was found to be always smaller than $\pm 30 \%$, whatever the device. Fig. 20 shows an example of the computed mean annual power in function of the drag coefficient applied in the numerical model for the case of the self-reacting two-body heaving device.

Here, we have to make a distinction for the cases of the floating OWC and the array of heaving buoys on a fixed platform. In the latter case, the uncertainty associated with the modelling of drag forces was found to be negligible. However, the modelling did not take into account the wave interactions effect between the buoys. Based on [40], the associated uncertainty was estimated to be about $\pm 20 \%$. 


\section{Small bottom-referenced heaving buoy (Bref-HB)}

\section{Working principle}

The device consists of an axi-symmetric buoy with ellipsoidal cross section floating on the ocean surface. Through a wire it is connected to a machinery unit standing at the sea bottom. The machinery consists of a linear generator placed inside a steel hull mounted on a concrete ballast structure. Under wave action, the buoy moves in surge and heave, resulting in a wire pull that drives the generator.

\section{Main dimensions and parameters}

\begin{tabular}{lcl} 
Property & Value & Unit \\
\hline Diameter & 3.0 & $\mathrm{~m}$ \\
Draft & 0.63 & $\mathrm{~m}$ \\
Displacement & 2.83 & $\mathrm{~m}^{3}$ \\
Mass of the buoy & 1000 & $\mathrm{~kg}$ \\
Stroke length & 1.8 & $\mathrm{~m}$ \\
\hline PTO model & \multicolumn{2}{c}{ Linear } \\
\hline Char. surface area & 42 & $\mathrm{~m}^{2}$ \\
Characteristic mass & 31 & $\mathrm{Mg}$ \\
\hline Water depth & 40 to 100 & $\mathrm{~m}$ \\
\hline
\end{tabular}

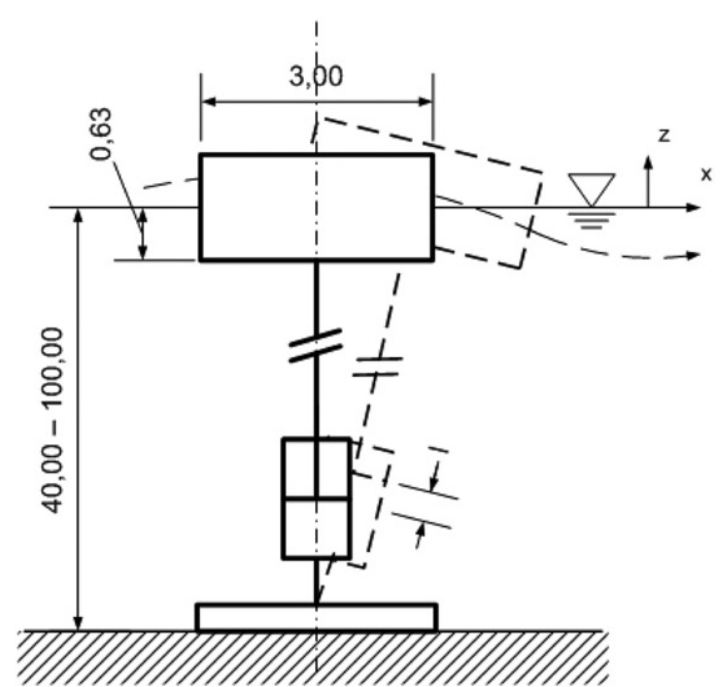

Power matrix

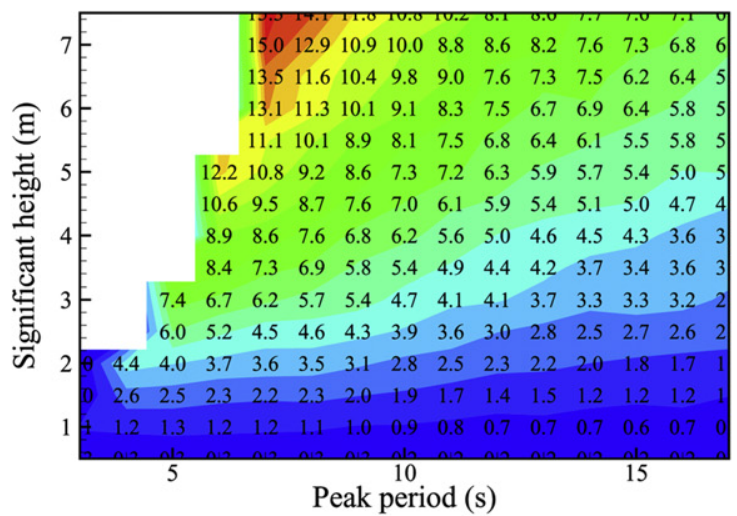

Estimates of performance measures

\begin{tabular}{cccccc} 
Site & SEMREV & EMEC & Yeu & Lisbon & Belmullet \\
\hline $\begin{array}{c}\text { Annual mean absorbed } \\
\text { power (kW) }\end{array}$ & 1.6 & 2.8 & 3.3 & 3.5 & 5.0 \\
$\begin{array}{c}\text { Capture width ratio } \\
\text { (\%) }\end{array}$ & 3.6 & 4.2 & 4.1 & 3.1 & 2.1 \\
$\begin{array}{c}\text { Absorbed energy per } \\
\text { characteristic mass (kWh/kg) } \\
\left.\begin{array}{c}\text { Absorbed energy per } \\
\text { surface area (MWh/m }\end{array}\right)\end{array}$ & 0.46 & 0.78 & 0.92 & 1.0 & 1.4 \\
$\begin{array}{c}\text { Absorbed energy per RMS } \\
\text { of PTO force }(\mathrm{kWh} / \mathrm{N})\end{array}$ & 1.5 & 2.1 & 2.3 & 2.2 & 2.6 \\
\hline
\end{tabular}

Capture width ratio is here defined as the ratio of capture width and the diameter of the buoy. The uncertainty on the annual mean absorbed power is estimated to be in the range of $[-20,+20 \%]$. 


\section{Bottom-referenced submerged heave-buoy (Bref-SHB)}

\section{Working principle}

This device consists of a submerged buoy close to the free surface. Through a wire it is connected to a hydraulic power take off system standing at the sea bottom.

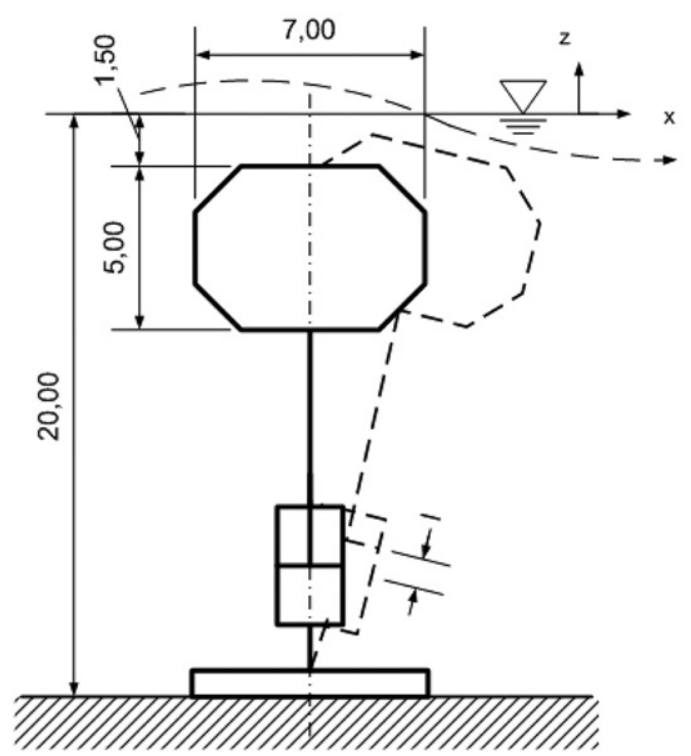

Main dimensions and parameters Power matrix

\begin{tabular}{lcl} 
Property & Value & Unit \\
\hline Diameter & 7.0 & $\mathrm{~m}$ \\
Height & 5.0 & $\mathrm{~m}$ \\
Displacement & 148. & $\mathrm{~m}^{3}$ \\
Mass of the buoy & 35. & $\mathrm{Mg}$ \\
Stroke length & 6. & $\mathrm{~m}$ \\
\hline PTO model & \multicolumn{2}{c}{ Linear } \\
\hline Char. surface area & 220 & $\mathrm{~m}^{2}$ \\
Characteristic mass & 200 & $\mathrm{Mg}$ \\
\hline Water depth & 20 & $\mathrm{~m}$ \\
\hline
\end{tabular}

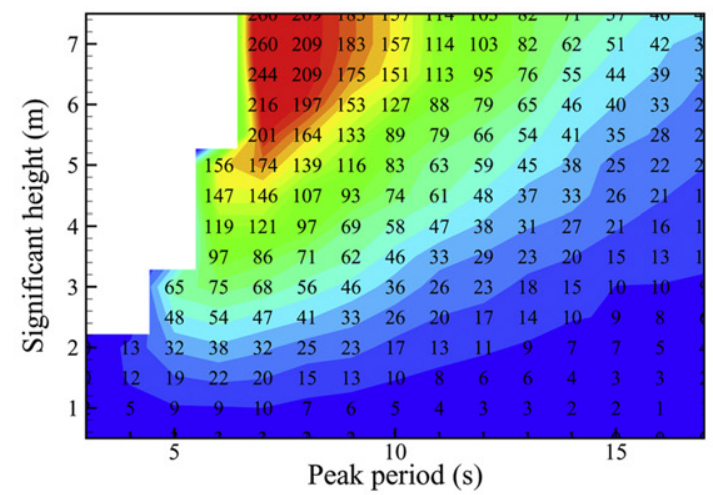

\section{Estimates of performance measures}

\begin{tabular}{|c|c|c|c|c|c|}
\hline Site & SEMREV* & EMEC* & Yeu* & Lisbon* & Belmullet* \\
\hline $\begin{array}{l}\text { Annual mean absorbed } \\
\text { power }(\mathrm{kW})\end{array}$ & 8.8 & 18.5 & 22 . & 19. & 31. \\
\hline $\begin{array}{c}\text { Capture width ratio } \\
(\%)\end{array}$ & 9 & 13 & 13 & 8 & 6 \\
\hline $\begin{array}{c}\text { Absorbed energy per } \\
\text { characteristic mass }(\mathrm{kWh} / \mathrm{kg})\end{array}$ & 0.39 & 0.81 & 0.97 & 0.83 & 1.37 \\
\hline $\begin{array}{l}\text { Absorbed energy per } \\
\text { surface area }\left(\mathrm{MWh} / \mathrm{m}^{2}\right)\end{array}$ & 0.35 & 0.74 & 0.88 & 0.76 & 1.24 \\
\hline $\begin{array}{l}\text { Absorbed energy per RMS } \\
\text { of PTO force }(\mathrm{kWh} / \mathrm{N})\end{array}$ & 1.53 & 2.1 & 2.4 & 3.8 & 2.9 \\
\hline
\end{tabular}

Fig. 13. Summary sheet for the bottom-referenced submerged heave-buoy (Bref-SHB). 


\section{Floating two-body heaving converter (F-2HB)}

\section{Working principle}

This device consists of an axi-symmetric, self-reacting two-body system, operating in the heave mode. It is composed of a low-draft torus sliding along a high-draft float. It has a hydraulic PTO system, which is driven by the relative motion between the two bodies.

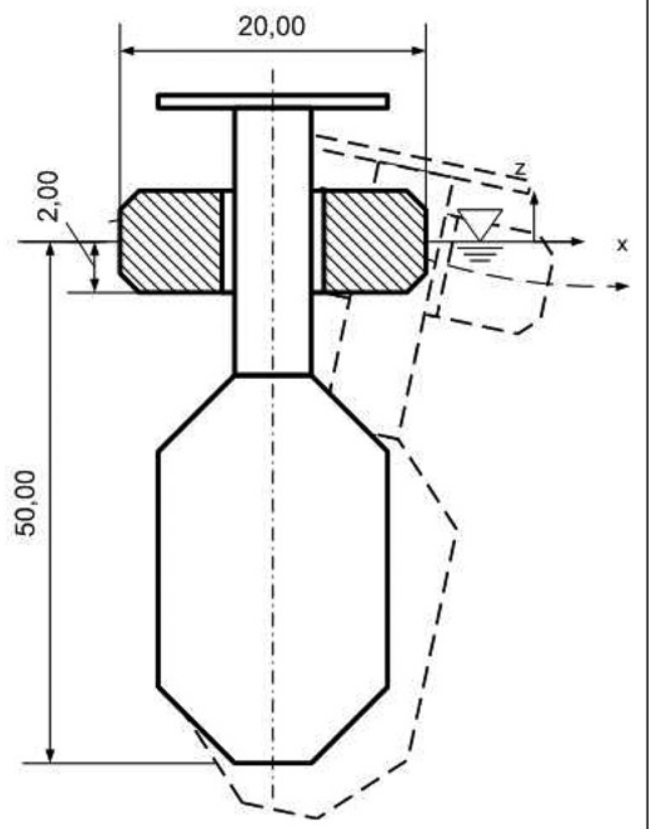

\section{Main dimensions and parameters Power matrix}

\begin{tabular}{lcl} 
Property & Value & Unit \\
\hline Torus diameter & 20.0 & $\mathrm{~m}$ \\
Torus draft & 2.0 & $\mathrm{~m}$ \\
Float draft & 50.0 & $\mathrm{~m}$ \\
Displacement & 4960. & $\mathrm{~m}^{3}$ \\
Mass of torus & 278. & $\mathrm{Mg}$ \\
Mass of float & 4680. & $\mathrm{Mg}$ \\
Stroke length & 6. & $\mathrm{~m}$ \\
\hline PTO model & \multicolumn{2}{c}{ Linear } \\
\hline Char. surface area & 2120 & $\mathrm{~m}^{2}$ \\
Characteristic mass & 5704 & $\mathrm{Mg}$ \\
\hline Water depth & Deep & $\mathrm{m}$ \\
\hline
\end{tabular}

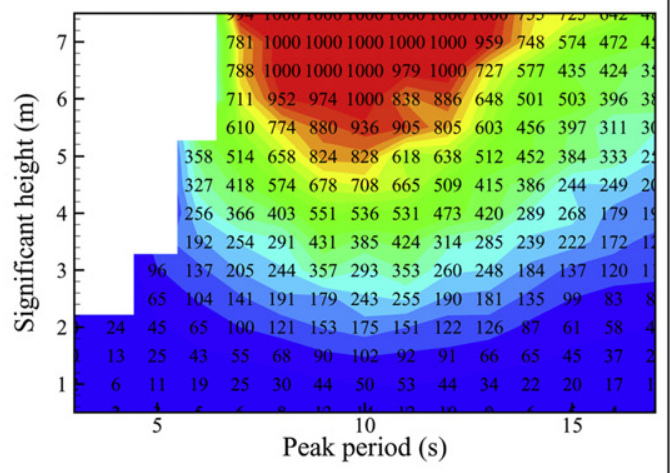

\section{Estimates of performance measures}

\begin{tabular}{|c|c|c|c|c|c|}
\hline Site & SEMREV & EMEC & Yeu & Lisbon & Belmullet \\
\hline $\begin{array}{c}\text { Annual mean absorbed } \\
\text { power }(\mathrm{kW})\end{array}$ & 79. & 127. & 191. & 199. & 373. \\
\hline $\begin{array}{c}\text { Capture width ratio } \\
(\%)\end{array}$ & 27. & 29. & 36. & 27. & 23. \\
\hline $\begin{array}{c}\text { Absorbed energy per } \\
\text { characteristic mass }(\mathrm{kWh} / \mathrm{kg})\end{array}$ & 0.12 & 0.20 & 0.30 & 0.30 & 0.57 \\
\hline $\begin{array}{c}\text { Absorbed energy per } \\
\text { surface area }\left(\mathrm{MWh} / \mathrm{m}^{2}\right)\end{array}$ & 0.33 & 0.53 & 0.79 & 0.82 & 1.54 \\
\hline $\begin{array}{c}\text { Absorbed energy per RMS } \\
\text { of PTO force }(\mathrm{kWh} / \mathrm{N})\end{array}$ & 1.2 & 1.7 & 2.0 & 2.0 & 2.7 \\
\hline
\end{tabular}

Capture width ratio is here defined as the ratio of capture width and the diameter of the buoy. The uncertainty of the annual mean absorbed power is estimated to be in the range of $[-20,+40 \%]$. 


\section{Bottom-fixed heave-buoy array (B-HBA)}

\section{Working principle}

This system is composed of many floats connected to a single jack-up structure. The jack-up structure stands on the seabed and provides a fixed reference to the floats. The floats are submerged hemispheres. Each one is connected to the main structure via an arm and a hinge. With the action of the waves, each float moves up and down. The relative motion between floats and the structure is converted into useful energy via hydraulic rams.

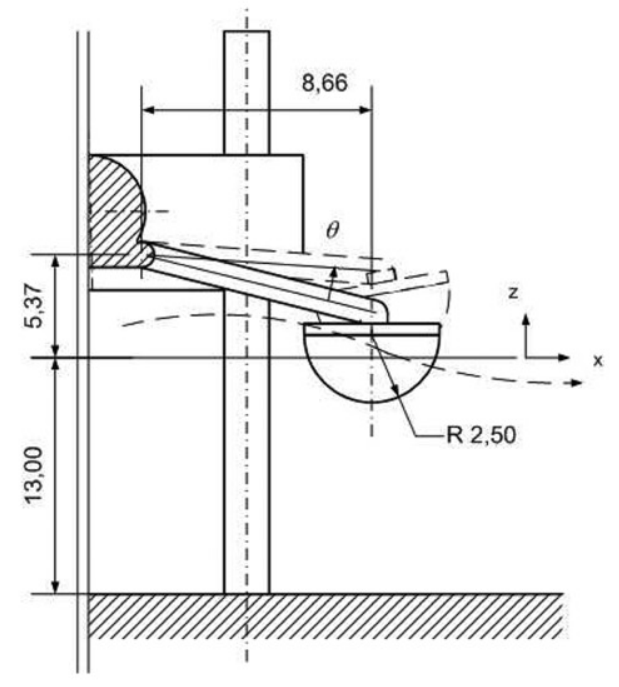

Main dimensions and parameters Power matrix

\begin{tabular}{lcl} 
Property & Value & Unit \\
\hline Float diameter & 5.0 & $\mathrm{~m}$ \\
Float height & 5.0 & $\mathrm{~m}$ \\
Float displacement & 25.5 & $\mathrm{~m}^{3}$ \\
Float mass & 35. & $\mathrm{Mg}$ \\
Number of floats & 20 & \\
Length of structure & 70. & $\mathrm{~m}$ \\
Width of structure & 17. & $\mathrm{~m}$ \\
Structure mass & 900. & $\mathrm{Mg}$ \\
\hline PTO model & \multicolumn{2}{c}{ Linear } \\
\hline Char. surface area & 4350 & $\mathrm{~m}^{2}$ \\
Characteristic mass & 1600 & $\mathrm{Mg}$ \\
\hline Water depth & 13. & $\mathrm{~m}$ \\
\hline
\end{tabular}

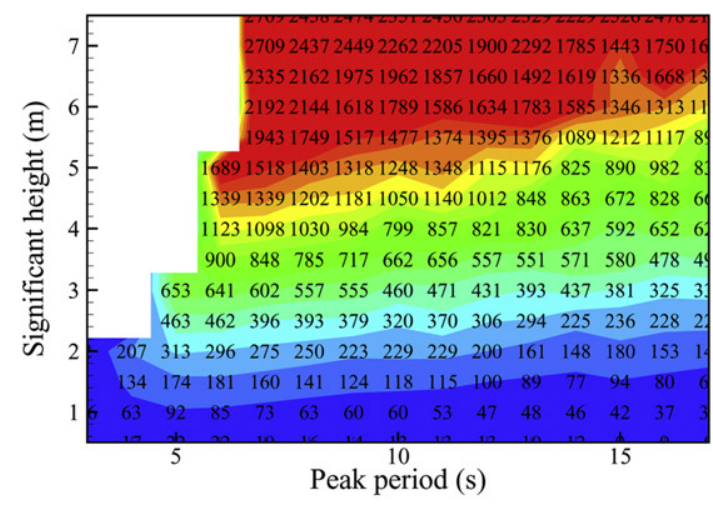

Estimates of performance measures

\begin{tabular}{|c|c|c|c|c|c|}
\hline Site & SEMREV* & EMEC* & Yeu* & Lisbon* & Belmullet* \\
\hline $\begin{array}{l}\text { Annual mean absorbed } \\
\text { power }(\mathrm{kW})\end{array}$ & 127. & 225 . & 280 & 303. & 612. \\
\hline $\begin{array}{c}\text { Capture width ratio } \\
\text { (\%) }\end{array}$ & 14. & 16. & 17. & 12. & 12. \\
\hline $\begin{array}{c}\text { Absorbed energy per } \\
\text { characteristic mass }(\mathrm{kWh} / \mathrm{kg})\end{array}$ & 0.69 & 1.2 & 1.5 & 1.7 & 3.4 \\
\hline $\begin{array}{c}\text { Absorbed energy per } \\
\text { surface area }\left(\mathrm{MWh} / \mathrm{m}^{2}\right)\end{array}$ & 0.25 & 0.45 & 0.56 & 0.61 & 1.23 \\
\hline $\begin{array}{l}\text { Absorbed energy per RMS } \\
\text { of PTO force }(\mathrm{kWh} / \mathrm{N})\end{array}$ & 0.93 & 1.2 & 1.2 & 1.1 & 1.6 \\
\hline
\end{tabular}

Fig. 15. Summary sheet for the bottom-fixed heave-buoy array (B-HBA). 


\section{Floating heave-buoy array (F-HBA)}

\section{Working principle}

This system is a multibody floating WEC, composed of many heaving buoys connected to a common submerged reference structure. This structure is composed of an arrangement of a single support structure and a series of ballasts baskets, connected through tension wires. The total buoyancy force from the buoys is balanced by net gravity forces of the bridge and the ballast baskets. The buoys are connected to the submerged structure via a hydraulic PTO system, which converts the energy.

\begin{tabular}{lcl}
\multicolumn{3}{l}{ Main dimensions and parameters } \\
Property & Value & Unit \\
\hline Float diameter & 8.0 & $\mathrm{~m}$ \\
Float draft & 13.4 & $\mathrm{~m}$ \\
Float displacement & 406. & $\mathrm{~m}^{3}$ \\
Float mass & 364. & $\mathrm{Mg}$ \\
Number of floats & 10 & \\
Length of structure & 132. & $\mathrm{~m}$ \\
Width of structure & 18. & $\mathrm{~m}$ \\
Structure mass & 467. & $\mathrm{Mg}$ \\
\hline PTO model & Coulomb damp. \\
\hline Char. surface area & 4750 & $\mathrm{~m}$ \\
Characteristic mass & 5233 & $\mathrm{Mg}$ \\
\hline Water depth & Deep & $\mathrm{m}$ \\
\hline
\end{tabular}

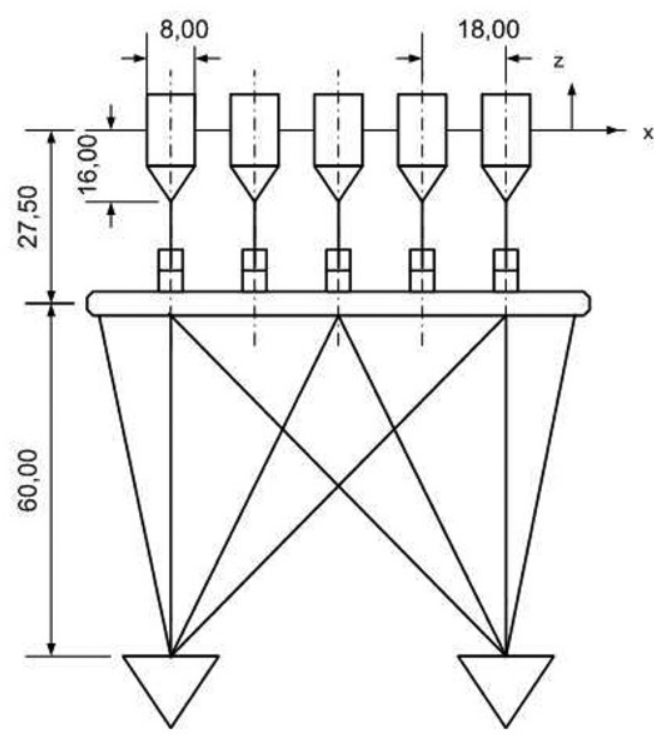

Power matrix

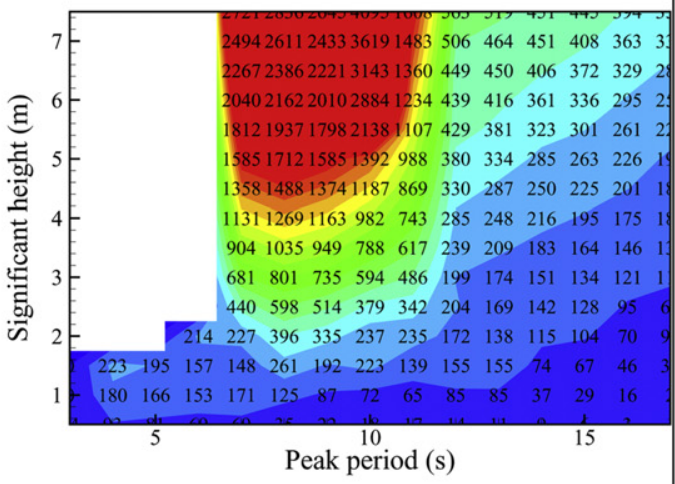

Estimates of performance measures

\begin{tabular}{|c|c|c|c|c|c|}
\hline Site & SEMREV & EMEC & Yeu & Lisbon & Belmullet \\
\hline $\begin{array}{c}\text { Annual mean absorbed } \\
\text { power }(\mathrm{kW})\end{array}$ & 224. & 326. & 409. & 317. & 417. \\
\hline $\begin{array}{c}\text { Capture width ratio } \\
(\%)\end{array}$ & 11. & 11. & 11. & 6.4 & 3.9 \\
\hline $\begin{array}{c}\text { Absorbed energy per } \\
\text { characteristic mass }(\mathrm{kWh} / \mathrm{kg})\end{array}$ & 0.37 & 0.54 & 0.67 & 0.52 & 0.68 \\
\hline $\begin{array}{l}\text { Absorbed energy per } \\
\text { surface area }\left(\mathrm{MWh} / \mathrm{m}^{2}\right)\end{array}$ & 0.43 & 0.63 & 0.79 & 0.61 & 0.80 \\
\hline $\begin{array}{l}\text { Absorbed energy per RMS } \\
\text { of PTO force }(\mathrm{kWh} / \mathrm{N})\end{array}$ & $\mathrm{N} / \mathrm{A}$ & N/A & 1.32 & $\mathrm{~N} / \mathrm{A}$ & $\mathrm{N} / \mathrm{A}$ \\
\hline
\end{tabular}

Capture width ratio is here defined as the ratio of capture width and the length of the structure. The uncertainty of the annual mean absorbed power is estimated to be in the range of $[-10,+25 \%]$. 


\section{Bottom-fixed oscillating flap (B-OF)}

\section{Working principle}

This device is a simple pitching flap, oscillating about a fixed axis close to the sea bottom, and so is suitable for shallow and intermediate water depth. It has a hydroelectric machinery system, where a pump placed at the rotating shaft pumps pressurised hydraulic oil to a shoreline station. There the hydraulic energy is used to drive an electric generator.

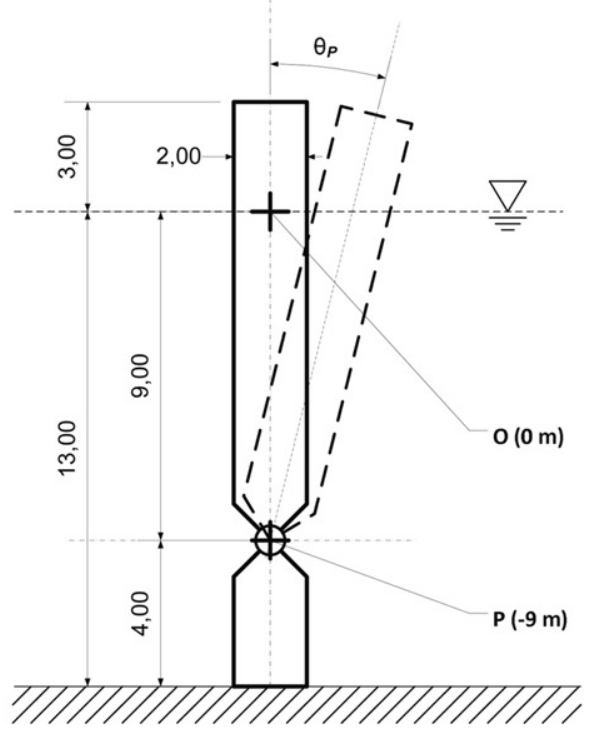

Main dimensions and parameters Power matrix

\begin{tabular}{lcc} 
Property & Value & Unit \\
\hline Width & 26. & $\mathrm{~m}$ \\
Draft & 9. & $\mathrm{~m}$ \\
Thickness & 2. & $\mathrm{~m}$ \\
Hinge height from & 4. & $\mathrm{~m}$ \\
seabed & & \\
Mass & 150. & $\mathrm{Mg}$ \\
Displacement & 442 & $\mathrm{~m}^{3}$ \\
\hline PTO model & \multicolumn{2}{c}{$\mathrm{Linear}^{2}$} \\
\hline Char. surface area & 2020 & $\mathrm{~m}^{2}$ \\
Characteristic mass & 3800 & $\mathrm{Mg}$ \\
\hline Water depth & 13 & $\mathrm{~m}$ \\
\hline
\end{tabular}

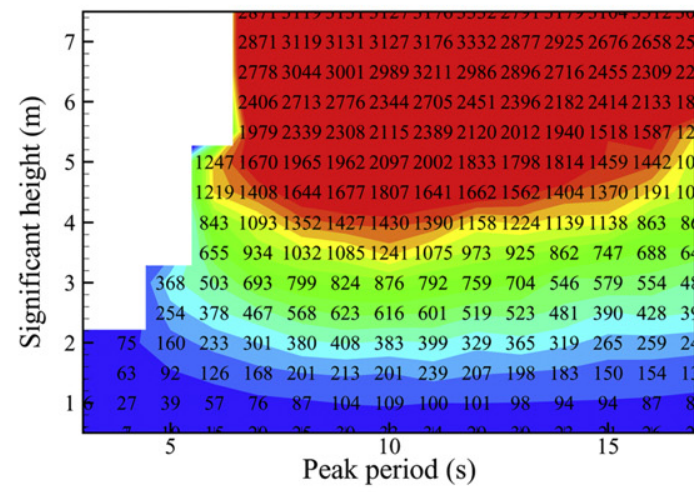

Estimates of performance measures

\begin{tabular}{|c|c|c|c|c|c|}
\hline Site & SEMREV* & EMEC* & $\mathrm{Yeu}^{*}$ & Lisbon* & Belmullet* \\
\hline $\begin{array}{c}\text { Annual mean absorbed } \\
\text { power }(\mathrm{kW})\end{array}$ & 211. & 348. & 440. & 513. & 981. \\
\hline $\begin{array}{c}\text { Capture width ratio } \\
(\%)\end{array}$ & 61. & 68. & 72. & 58. & 52. \\
\hline $\begin{array}{c}\text { Absorbed energy per } \\
\text { characteristic mass }(\mathrm{kWh} / \mathrm{kg})\end{array}$ & 0.49 & 0.8 & 1.0 & 1.2 & 2.3 \\
\hline $\begin{array}{c}\text { Absorbed energy per } \\
\text { surface area }\left(\mathrm{MWh} / \mathrm{m}^{2}\right)\end{array}$ & 0.92 & 1.5 & 1.9 & 2.2 & 4.2 \\
\hline $\begin{array}{l}\text { Absorbed energy per RMS } \\
\text { of PTO force }(\mathrm{kWh} / \mathrm{N})\end{array}$ & $\mathrm{N} / \mathrm{A}$ & 1.1 & 1.4 & 1.6 & 6.6 \\
\hline
\end{tabular}

Fig. 17. Summary sheet for the bottom-fixed oscillating flap (B-OF). 


\section{Floating three-body oscillating flap device (F-3OF)}

\section{Working principle}

This device consists in four hinged flaps attached to the same floating structure. Via PTO systems, the relative motion between each flap and the structure is converted into useful energy.

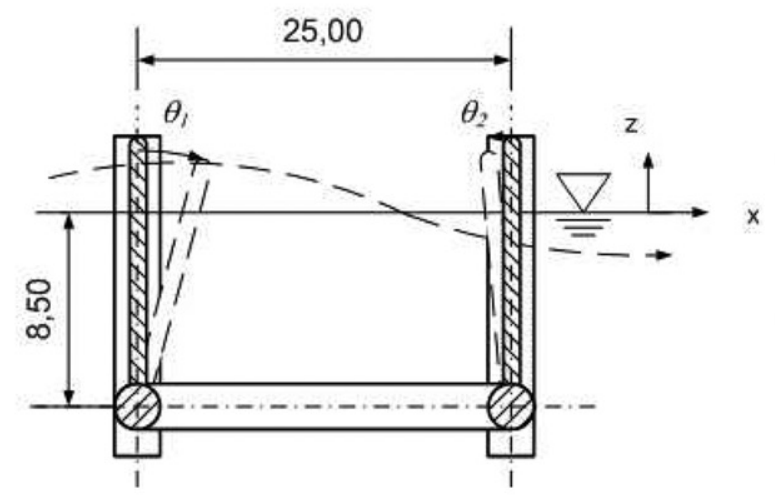

Main dimensions and parameters Power matrix

\begin{tabular}{lcl} 
Property & Value & Unit \\
\hline Flap width & 9.5 & $\mathrm{~m}$ \\
Flap draft & 8.5 & $\mathrm{~m}$ \\
Displacement & 185. & $\mathrm{~m}^{3}$ \\
Number of flaps & 4 & \\
Structure length & 25. & $\mathrm{~m}$ \\
Structure width & 25. & $\mathrm{~m}$ \\
Structure draft & 12. & $\mathrm{~m}$ \\
Displacement & 673. & $\mathrm{~m}^{3}$ \\
\hline PTO model & \multicolumn{2}{c}{ Linear } \\
\hline Char. surface area & 2160 & $\mathrm{~m}^{2}$ \\
Characteristic mass & 1622 & $\mathrm{Mg}$ \\
\hline Water depth & Deep & $\mathrm{m}$ \\
\hline
\end{tabular}

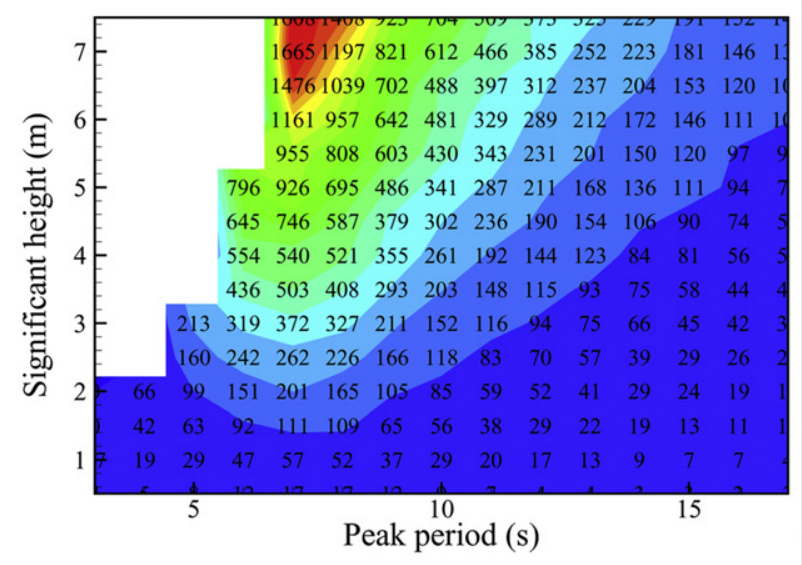

Estimates of performance measures

Site

Annual mean absorbed power $(\mathrm{kW})$

Capture width ratio

(\%)

Absorbed energy per characteristic mass $(\mathrm{kWh} / \mathrm{kg})$

Absorbed energy per surface area $\left(\mathrm{MWh} / \mathrm{m}^{2}\right)$

Absorbed energy per RMS of PTO force $(\mathrm{kWh} / \mathrm{N})$
SEMREV

EMEC Yeu Lisbon Belmullet

52.

112

$131 . \quad 104$.

145.

14.

20

20.

11.

7.

0.28

0.60

0.69

0.57

0.78

0.21

0.46

0.51

0.42

0.6

1.1

1.4

1.6

1.5

1.5

Capture width ratio is here defined as the ratio of capture width and the width of the structure. The uncertainty of the annual mean absorbed power is estimated to be in the range of $[-25,+30 \%]$. 


\section{Floating oscillating water column (F-OWC)}

\section{Working principle}

This device is a particular type of OWC device known as the backward bent duct buoy (BBDB). It has a single air chamber and is free to move in six degrees of freedom. The water column inlet is on the downstream side of the device. The hull is constructed of thin steel walls enclosing the water column. The power conversion is provided by means of an air turbine connected to an electric generator. The motion of the water column relative to the OWC body creates oscillating pressure in the chamber and air flow through the turbine.

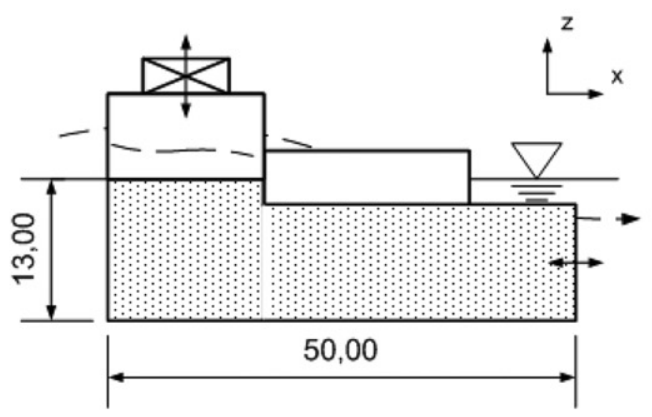

\section{Main dimensions and parameters}

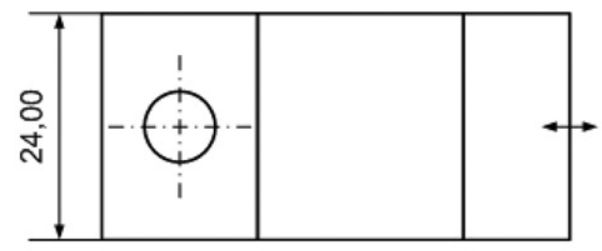

\begin{tabular}{lcc} 
& & \\
Property & Value & Unit \\
\hline Length & 50. & $\mathrm{~m}$ \\
Width & 24. & $\mathrm{~m}$ \\
Draft & 13. & $\mathrm{~m}$ \\
\hline PTO model & \multicolumn{2}{c}{ Linear } \\
\hline Char. surface area & 6500 & $\mathrm{~m}^{2}$ \\
Characteristic mass & 1800 & $\mathrm{Mg}$ \\
\hline Water depth & Deep & $\mathrm{m}$ \\
\hline
\end{tabular}

\section{Power matrix}

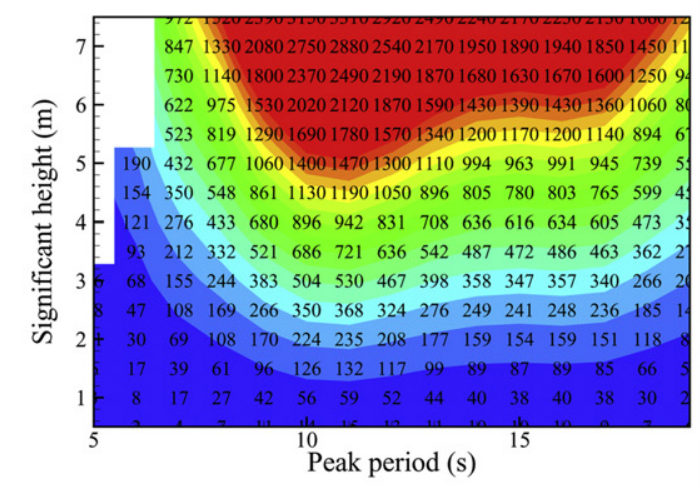

Power matrix

Estimates of performance measures

\begin{tabular}{cccccc} 
Site & SEMREV & EMEC & Yeu & Lisbon & Belmullet \\
\hline $\begin{array}{c}\text { Annual mean absorbed } \\
\text { power (kW) }\end{array}$ & 147. & 262. & 337. & 367. & 745. \\
$\begin{array}{c}\text { Capture width ratio } \\
(\%)\end{array}$ & 41 & 50. & 52. & 41. & 38. \\
$\begin{array}{c}\text { Absorbed energy per } \\
\text { characteristic mass (kWh/kg) } \\
\begin{array}{c}\text { Absorbed energy per } \\
\text { surface area }\left(\mathrm{MWh} / \mathrm{m}^{2}\right)\end{array}\end{array}$ & 0.7 & 1.3 & 1.6 & 1.8 & 3.6 \\
$\begin{array}{c}\text { Absorbed energy per RMS } \\
\text { of PTO force }(\mathrm{kWh} / \mathrm{N})\end{array}$ & N/A & N/A & N/A & N/A & N/A \\
\hline
\end{tabular}

Capture width ratio is here defined as the ratio of capture width and the width of the barge. The uncertainty of the annual mean absorbed power is estimated to be in the range of $[-25,+25 \%]$. 


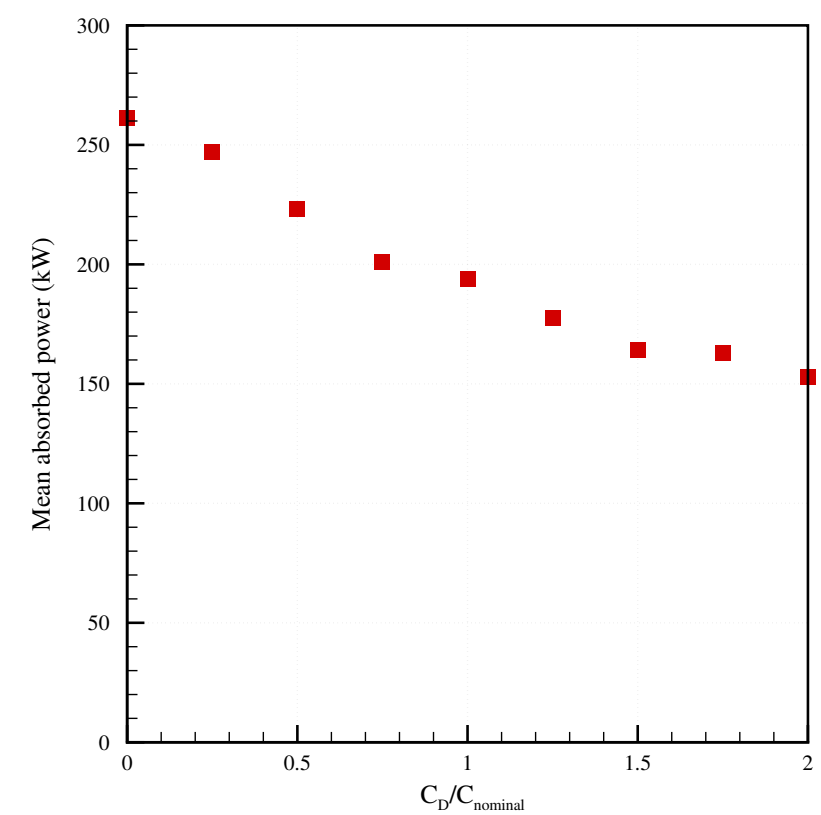

Fig. 20. Mean annual absorbed power in function of applied drag coefficient ratio for the self-reacting two-body heaving device.

In the case of the floating OWC, losses were taken into account through additional linear damping terms. They are applied to the body by introducing a diagonal damping matrix with constant values over the whole frequency range, taken as a certain percentage of the radiation damping. This has the effect of reducing the body motions. Another damping coefficient is also introduced with the effect of reducing the volume flow through the mean internal water surface. Uncertainty limits were obtained by taking these damping coefficients to be zero and twice the nominal values. They were found to be about $\pm 25 \%$.

For the performance measures related to mass and surface area, a small uncertainty is also attributed to the estimation of the characteristic values. In particular, the rough estimation of characteristic mass for the self-referenced floating converters should be expected to have an uncertainty of about $10 \%$.

It should be noted that all results have been derived with the assumption that the PTO parameters are kept at constant values optimised for each sea state. If highly efficient machinery solutions can be developed for reactive control or other phase control realisations, then wave-by-wave control may become a viable strategy. It may then be expected that the devices with the most narrow-banded natural responses (i.e. responses without any PTO damping applied) will have the most to earn from such techniques. As no example of successful and robust application of such a strategy in practise have been reported, no uncertainty has been attributed to this choice here.

\subsection{Performance measures}

Consider first the capture width ratios in Figs. 12-19. One can see that they vary somewhat with the site, but not as much as the power absorption figures. Thus, it shows that capture width ratio can be a very useful number if one wants to make a quick estimate of the energy absorption of a device for a given wave energy resource. Here it is worth noticing that the capture width ratios we obtained are in agreement with the ones which were found in [2].

It appears that the capture width ratios reach their maxima for the Yeu site. For this site, the wave resource is also of the order
$25 \mathrm{~kW} / \mathrm{m}$ which can be considered as a reasonable average for wave energy resources. For a higher level of resource, the number of possible sites would be much smaller, meaning a smaller market, whereas for lower levels of resource it would be more difficult to achieve economic viability.

Therefore, the Yeu site was selected for comparing the performance measures of the different devices. The comparison is shown in Fig. 21. From top to bottom we find the mean annual power, the mean annual absorbed energy per mass, the mean annual absorbed energy per surface area and the mean annual absorbed energy per RMS of PTO force, for each of the eight devices.

The top figure shows how different the mean annual absorbed power can be from one device to another. It illustrates well the wide diversity in wave energy concepts. The ratio is about 140 between the device with the smallest power absorption and the device with the largest one.

However, one should notice that they are also respectively the smallest and biggest devices, and that the ratio of masses is about the same magnitude. So if one takes the ratio of annual absorbed energy and characteristic mass, then the differences between the devices are considerably reduced. This is shown on the second figure from the top. The ratio of the maximum to the minimum of this performance measure is about 5, whereas it was 140 for mean power. Based on these results, one may roughly state that the annual energy absorption to characteristic mass ratio is in the order of $1 \mathrm{MWh} /$ tonne.

The comparison of the small bottom-referenced heaving buoy and the floating three-body oscillating flap device is particularly noticeable. Despite totally different working principles and a characteristic mass ratio of 45 , the ratio of absorbed energy to mass differs only by about $25 \%$.

Then consider the third performance measure, i.e. absorbed energy per characteristic surface area. Here, the ratio of maximum to the minimum is about 4 .

If the particular case of the bottom-fixed oscillating flap is excluded for the moment, this ratio is even seen to be smaller, about 1.3. A tentative explanation for why this last measure has only little variation between devices could be that wave forces are pressure forces. Power is pressure times volume stroke per time. Both the orders of magnitude of the wave pressure and the time (i.e. wave period) are the same for all the devices. That leaves us with volume stroke, which is area times stroke length. The stroke length is limited by mechanical constraints and the need for keeping viscous losses down, and ends up being of the same order for all devices. Accordingly, power should depend on wetted surface area, which could explain why the absorbed power per characteristic surface area is close for all devices. As an average, one could say that it is typically equal to $0.8 \mathrm{MWh} / \mathrm{m}^{2}$.

Considering now the case of the bottom-fixed oscillating flap, one can see that it has a much higher energy to surface area ratio than all of the other devices. The factor is about 2.5. It indicates that this working principle makes better use of its surface to capture wave energy. This can also explain the high capture width ratio of about $70 \%$. This capture width ratio is large, but one can note that it is in agreement with experimental results reported in [37].

To conclude on the performance measure of annual absorbed energy per surface area, we will retain that the order of magnitude is typically $1 \mathrm{MWh} / \mathrm{m}^{2}$, except for the bottom-fixed oscillating flap for which it is of order $2 \mathrm{MWh} / \mathrm{m}^{2}$.

In the bottom figure, one can see that also the ratio of annual absorbed energy to the RMS of PTO force exhibits only little variation with the device. Here again, maybe we should not be surprised, as the energy is the product of PTO force and stroke 

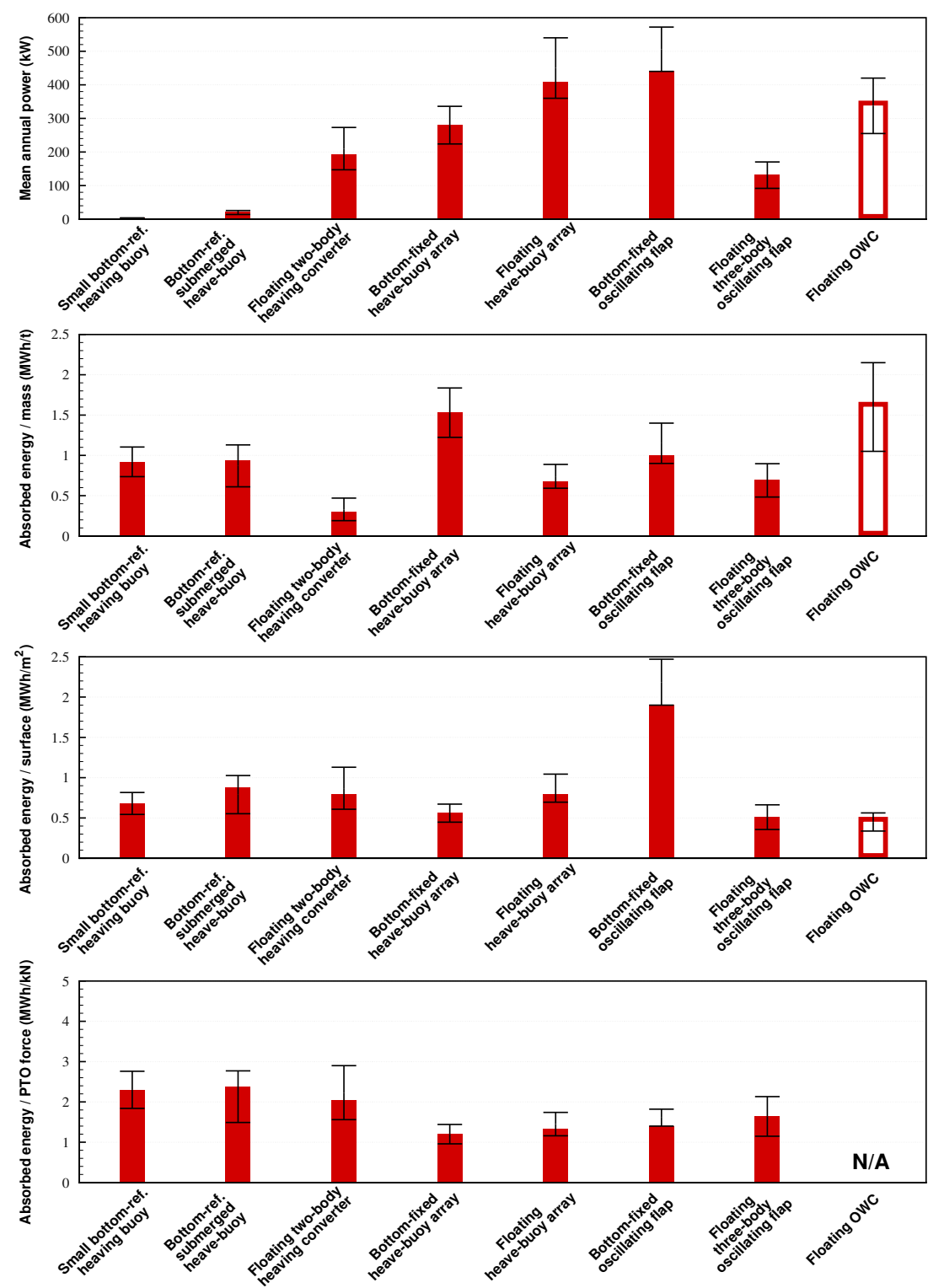

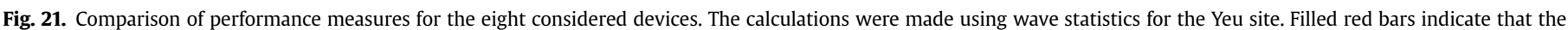

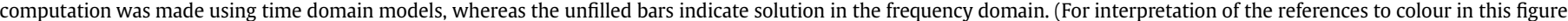
legend, the reader is referred to the web version of this article.)

length, and as different PTO systems have similar stroke lengths. Thus this performance measure is directly linked to the total stroke travelled during one year. As an average, one can say that its value is typically $2 \mathrm{MWh} / \mathrm{kN}=7200 \mathrm{~km}$.

\subsection{Parametric studies on maximum PTO power and rated power}

In the wave energy community, there are sometimes discussions on how the rated power of a device, and the resulting capacity factor (defined as the ratio of the averaged power to the rated power) should be defined. There is also sometimes confusion between the maximum instantaneous power of the PTO system and the rated power of the WEC. In the following, we will present our views on this and we will show how the rated power could be roughly estimated from the knowledge of the mean annual absorbed power. This also directly gives and estimate for the capacity factor.
First, let us distinguish between the absorbed power and the output power (also called delivered power or useful power). We take the absorbed power as the power that flows from the mechanical system (oscillating body or water column) into the PTO system. It is then equal to the PTO force times the velocity for the productive degree of freedom, depending on the PTO system. Because waves are oscillations the velocity is oscillating, and thus the instantaneous absorbed power is oscillatory too, going to zero twice per cycle. Fig. 22 shows an example of the instantaneous absorbed power in the case of the floating two-body heaving device. The incident wave is irregular with peak period $9 \mathrm{~s}$ and significant height $2.5 \mathrm{~m}$. One can can see that the instantaneous absorbed power stays within the range between 0 and $2 \mathrm{MW}$ which has been set as the maximum power of the PTO system in this case. In other words, we define the maximum PTO power as the maximum of instantaneous power that can be absorbed by the PTO system. 


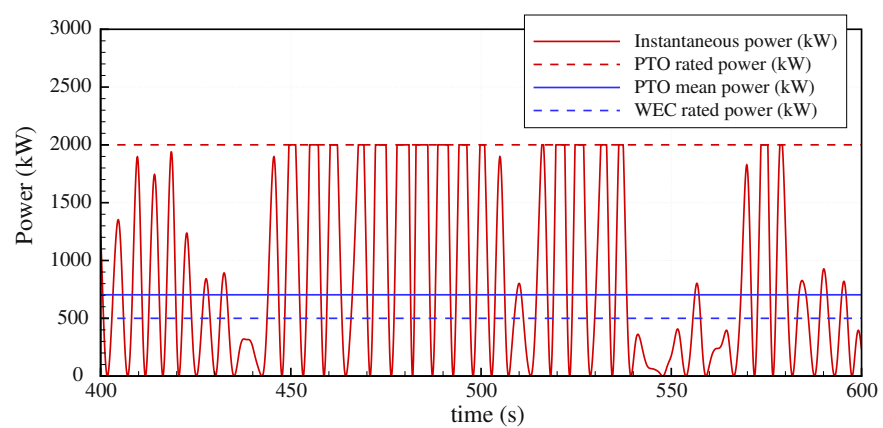

Fig. 22. Instantaneous and mean absorbed power by the floating two-body heaving device, in an irregular wave of peak period $9 \mathrm{~s}$ and significant height of $2.5 \mathrm{~m}$. Also shown is the maximum PTO power and the rated power.

Further let us define the output power of the WEC. Of course, the instantaneous power absorbed by the PTO system is too oscillatory to be sent directly to the grid. It has to be smoothed, e.g. by using energy storage components such as hydraulic accumulators, flywheels, batteries [41] or super-capacitors [42]. The output of these storage components, which is delivered to the grid, is what we mean by output power. It may still have considerable variation, but the maximum capacity may be well described by a mean value; this is what we define as the rated power of the WEC.

The mean output power will necessarily be smaller than the mean absorbed power due to losses in the conversion and storage components. If the mean absorbed power exceeds the rated power, the excess power will have to be dissipated, or the device motion must be controlled in order to reduce the power absorption. In the example of Fig. 22, the average absorbed power is $703 \mathrm{~kW}$, whereas we have set the rated power to $500 \mathrm{~kW}$. The consequence is that the smoothing system will not be able to deal with the difference of (703-500) $\mathrm{kW}=203 \mathrm{~kW}$. In analysis of the numerical simulation we therefore consider the difference as lost, and the mean output power becomes equal to the rated power. In real operation of the

Table 2

Effect of limiting the instantaneous power or the mean rated power on the mean annual power absorption for some of the considered devices.

\begin{tabular}{llll}
\hline Device & Maximum & Rated & Mean annual \\
& PTO power $(\mathrm{kW})$ & power $(\mathrm{kW})$ & output power \\
\hline Small bottom-referenced & None & None & 2.4 \\
heaving buoy & 20 & None & 2.36 \\
Bottom-referenced submerged & None & None & 22. \\
heaving buoy & 200 & None & 21.7 \\
& 400 & None & 21.7 \\
& None & 100 & 22 \\
Floating two-body & None & 200 & 22 \\
heaving converter & None & None & 191 \\
& 1000 & None & 159 \\
Bottom-fixed heave-buoy & 2000 & None & 182 \\
array & None & 1000 & 191 \\
& None & None & 280 \\
& 2000 & None & 246 \\
Bottom-fixed oscillating & 4000 & None & 275 \\
flap & None & 600 & 240 \\
& None & 1200 & 269 \\
& None & None & 280 \\
& 2000 & None & 246 \\
Floating three-body & 4000 & None & 275 \\
oscillating flap device & None & 1000 & 240 \\
& None & 2000 & 269 \\
& None & None & 219 \\
& 1000 & None & 200 \\
& 2000 & None & 216 \\
& None & 1000 & 214 \\
\hline
\end{tabular}

device the absorbed power would probably have to be reduced by controlling the motion.

As we can see, the settings for the maximum absorbed power and the rated power influence the mean annual output power. This effect was investigated in the following way: if the instantaneous absorbed power is larger than the maximum PTO power, then the difference is assumed to be lost. The same rule was applied to the relationship between mean absorbed power and rated power. Table 2 shows the results of mean annual output power which were obtained for 5 of the eight devices, as a function of the maximum PTO power and the rated power.

One can see that setting the maximum PTO power to 20 times the mean annual absorbed power does not significantly decrease the mean annual output power, whatever the device. Therefore, it could be used as a rule of thumb in the design of the power take off system: the maximum PTO power could be limited at least down to about 20 times the mean annual power. For the rated power, a factor of five would not significantly decrease the mean annual output power. Therefore, the rule of thumb would be here that the capacity factor of a WEC should be at least about 0.2 . The upper limit for the capacity factor will depend on how the size of the device is chosen relative to the rated power and the way the motion is controlled in practise.

\section{Conclusion}

In this study, eight wave energy converters with different working principle have been considered, and their performance at five prospective locations have been estimated. The aim was to compare them in terms of the following performance measures: annual absorbed energy for each WEC, per unit of characteristic mass, per unit of characteristic surface area and per unit of characteristic power take-off (PTO) force.

The power matrices of each WEC were computed by the use of numerical models such that the annual absorbed energy could be found. The models were formulated in the time domain in order to be able to deal with non-linear effects such as viscous losses and/or end stops. As the performance depends strongly on the PTO parameters, these were optimised for each sea state in order to maximise the energy absorption. Uncertainties in the numerical model were discussed and error bars were derived for each performance measure.

Matrices of absorbed power per sea state and estimates of the annual absorbed energy were given for each considered device, at each location. Based on these results, the following conclusions were drawn:

- The annual absorbed energy differs a lot, from $2 \mathrm{~kW}$ for the small bottom-referenced heaving buoy at the least energetic site up to $800 \mathrm{~kW}$ for the bottom-fixed oscillating flap at the most energetic site. This was to be expected, as the compared devices differ a lot in terms of size and working principle. It illustrates well the wide diversity of wave energy converters that are currently being developed. However, as soon as the absorbed energy was considered relative to dimensionrelated parameters, the differences were found to be much smaller.

- The average capture width ratio varies only weakly between different sites. Therefore this measure could be used to make rough estimates of the energy absorption for any device placed at a given site.

- The annual absorbed energy per characteristic mass was found to be in the order of $1 \mathrm{MWh} /$ tonne, whatever the device.

- The annual absorbed energy per characteristic surface area was found to be typically about $1 \mathrm{MWh} / \mathrm{m}^{2}$, with exception for the 
bottom-fixed oscillating flap which gives in the order of $2 \mathrm{MWh} / \mathrm{m}^{2}$.

- The annual absorbed energy per RMS of PTO force was found to be typically about $2 \mathrm{MWh} / \mathrm{kN}$, whatever the device.

- By limiting the maximum PTO power (respectively the rated power) to 20 times (respectively 5 times) the mean absorbed power, one would not significantly decrease the mean output power in comparison to larger power ratings.

We believe that the performance measures that were estimated in this study directly reflects the main cost drivers for a wave energy converter. The study has shown that each of them are quite similar for different devices, despite very different working principles. The presented values for these performance measures may be taken as criteria for required performance in order for a technology to be interesting, and can hopefully help to bring down the cost of wave energy.

\section{Acknowledgements}

This research was carried out as part of the Statkraft Ocean Energy Research Program, sponsored by Statkraft (www.statkraft. no), and in collaboration between Ecole Centrale de Nantes (ECN), the Centre for Ships and Ocean Structures (CeSOS) at NTNU and Statkraft. The finantial support is gratefully acknowledged. Thanks also go to all the developers and associates who have shared information and discussed the results with us: namely Halvar Gravråkmo from Uppsala University, Thomas Soulard and Jochem Weber from Wavebob, Julius Espedal from Langlee and Øyvind Rogne from NTNU, Morten Kramer from DTU and Enrique Vidal Sanchez from Wavestar, Marco Alves from the Wave Energy Centre, Giovanni Mattarolo and Marc Andreewsky from EDF and Arnaud Vazeille from EDF EN, and Nils Myklebust from Pontoon Power Converter. Finally, Aurélien Babarit would also like to thank CeSOS for hosting him during the realisation of this study.

\section{References}

[1] Falcáo AF de O. Wave energy utilization: a review of technologies. Renewable and Sustainable Energy Reviews 2009;14(3):899-918.

[2] Meyer NI, McDonal Arnskov M, Vad Bennetzen CE, Burcharth HF, Bunger J, Jacobsen V, et al. Bølgekraftprogram, Afslutningsrapport, RAMBØLL, Teknikerbyen 31, 2830 Virum, Denmark; 2002.

[3] Previsic M, Bedard R, Hagerman G. E2I EPRI assessment, offshore wave energy conversion devices. Electricity Innovation Institute; 2004. Technical report E2I EPRI WP - 004 - US - Rev 1.

[4] Mulligan RF. A simple model for estimating newbuilding costs. Maritime Economics \& Logistics 2008;10:310-21.

[5] Babarit A, Hals J, Muliawan M, Kurniawan A, Moan T, Krokstad J. Numerical estimation of energy delivery from a selection of wave energy converters - final report Ecole Centrale de Nantes \& Norges Teknisk-Naturvitenskapelige Universitet; 2011.

[6] Masuda Y, Kimura H, Liang X, Gao X, Mogensen RM, Anderson T. Regarding BBDB wave power generating plant. In: Proc. of the 2nd European wave power Conference; 1996. p. 1-3.

[7] Nielsen K, Pontes T. Generic and site related wave data; 2010. Final technical report, OES-IEA Document No: T02-1.1.

[8] Young R. Wind generated ocean waves. 1st ed. Amsterdam: Elsevier; 1999.

[9] Folley M, Whittaker TJT. Analysis of the nearshore wave energy resource. Renewable Energy 2009;34:1709-15.

[10] Evans DV. Hydrodynamics of ocean wave-energy utilization Iutam Symposium Lisbon/Portugal; 1985.

[11] Pizer D. Numerical prediction of the performance of a Solo Duck. University of Edinburgh; 1992. Technical report.

[12] Payne GS, Taylor JRM, Bruce T, Parkin P. Assessment of boundary-element method for modelling a free-floating sloped wave energy device. Part 2: experimental validation. Ocean Engineering 2008;35:342-57.

[13] Durand M, Babarit A, Pettinotti B, Quillard O, Toularastel JL, . Clément AH. Experimental validation of the performances of the SEAREV wave energy converter with real time latching control. In: Proc. of the 7th European wave and tidal energy conference; 2007. Porto, Portugal.

[14] Folley M, Whittaker TWT, van't Hoff J. The design of small seabed-mounted bottom-hinged wave energy converters. In: Proc. of the 7th European wave and tidal energy conference; 2007. Porto, Portugal.

[15] Kerbiriou M, Prevosto M, Maisondieu C, Babarit A, Clément AH. Influence of an improved sea-state description on a wave energy converter production. In: Proc. of the 26th international conference on offshore mechanics and arctic engineering; 2007. San Diego, California.

[16] Molin B. Hydrodynamique des Structures Offshore, Guides Pratiques sur les Ouvrages en Mer, Technip; 2002.

[17] Hals J, Bjarte-Larsson T, Falnes J. Optimum reactive control and control by latching of a wave-absorbing semisubmerged heaving sphere. In: Proc. of the 21st offshore mechanics and arctic engineering conference; 2002. p. 1-9.

[18] WAMIT Version 6.3 User Manual, http://www.wamit.com; 2006.

[19] Delhommeau G. Seakeeping codes aquadyn and aquaplus. In: Proc. of the 19th WEGEMT school, numerical simulation of hydrodynamics: ships and offshore structures; 1993.

[20] Morison JR, O'Brien MP, Johnson JW, Schaaf SA. The forces exerted by surface waves on piles. Petroleum Transactions of AIME 1950;189:149-57.

[21] Henderson R. Design, simulation and testing of a novel hydraulic power takeoff system for the pelamis wave energy converter. Renewable Energy 2006; 31(2):271-83.

[22] Eriksson M. Modelling and experimental verification of direct drive wave energy conversion - Buoy - generator dynamics, PhD thesis, Uppsala Universitet; 2007.

[23] Ruellan M, Ben Ahmed H, Multon B, Josset C, Babarit A, Clément AH. Design methodology for a SEAREV wave energy converter. IEEE Transactions on Energy Conversion 2010;25(3):760-7.

[24] Suzuki M. Design method of guide vane for wells turbine. Journal of Thermal Science 2006;15:126-31.

[25] Budal K, Falnes J, Hals T, Iversen LC, Onshus T. Model experiment with a phase controlled point absorber. In: Stephens HS, Stapleton CA, editors. Proceedings of second international symposium on wave and tidal energy. Cambridge, UK: ISBN 0-906085-43-9, pages 191-206; September 1981. p. 23-5. BHRA Fluid Engineering (Cranford, Bedford).

[26] Duclos G, Babarit A, Clément AH. Power take off damping optimisation with regard to wave climate. ASME Journal of Offshore Mechanics and Arctic Engineering 2006;128(1):56-64.

[27] Babarit A, Guglielmi M, Clément AH. Declutching control of a wave energy converter. Ocean Engineering 2009;36(12-13):1015-24.

[28] Falcao $\mathrm{F}$ de $\mathrm{O}$. Phase control through load control of oscillating-body wave energy converter with hydraulic PTO system. Ocean Engineering 2008; 35(3-4):358-66

[29] Cretel J, Lewis AW, Lightbody G, Thomas GP. An application of model predictive control to a wave energy point absorber. In: Proc. of the IFAC conference on control methodologies and technology for energy efficiency; 2010.

[30] Hals J, Falnes J, Moan T. A comparison of selected strategies for adaptive control of wave energy converters. Journal of Offshore Mechanics and Arctic Engineering August 2011;133(3). doi:10.1115/1.4002735. 031101.

[31] Blondel E, Bonnefoy F, Ferrant P. Deterministic non-linear wave prediction using probe data. Ocean Engineering 2010;37(10):913-26.

[32] Muliawan M, Gao Z, Moan T, Babarit A. Analysis of a two-body floating wave energy converter with particular focus on the effect of mooring system on energy capture. In: Proc. of the 30th international conference on ocean, offshore, and artic engineering; 2011.

[33] Vicente PC, Falcao AF de O, Justino PAP. Slack-chain mooring configuration analysis of a floating wave energy converter. In: Proc. of the 26th international workshop on water waves and floating bodies; 2011.

[34] Mouwen F. Presentation on wave bob to engineers Ireland. Downloaded from, www.engineersireland.ie; December, 9th, 2008. the 10th of September 2010.

[35] Kramer M. Info for Babarit - wave star C5, technical note; 2011.

[36] Pecher A, Kofoed JP, Espedal J, Hagberg S. Results of an experimental study of the Langlee wave energy converter. In: Proc. of the 20th international offshore and polar engineering conference; June 20-25, 2010. Beijing, China.

[37] Henry A, Doherty K, Cameron L, Whittaker T, Doherty R. Advances in the design of the Oyster wave energy converter. In: Proc. of the royal institution of naval architect s marine and offshore renewable energy conference; 2010. London, UK.

[38] Marintek. SIMO user manual program version 3.6; August 2008.

[39] DNV. HydroD user manual program version 1.1; January 2004.

[40] De Backer G, Vantorre M, Beels C, De Rouck D, Frigaard P. Power absorption by closely spaced point absorbers in constrained conditions. IET Renewable Power Generation 2010;4(6):579-91.

[41] Salter SH, Taylor JRM, Caldwell NJ. Power conversion mechanisms for wave energy. In: Proc. of the institution of mechanical engineers. Part M - Journal of Engineering for the Maritime Environment, 216; 2002. p. 1-27.

[42] Aubry J, Bydlowski P, Multon B, Ben Ahmed H, Borgarino B. Energy storage system for smoothing power generation of direct wave energy converters. In: Proc. of the 3rd international conference on ocean energy; 2010. 6 October, Bilbao, Spain. 